\title{
Análisis de la viabilidad de implementación en dispositivos móviles de BananaDesk
}

\author{
Property Management System \\ para alojamientos independientes
}

Trabajo Final

Maestría en Dirección de Empresas

Lic. María Luisina Cimatti

Director:

Dr. Eduardo Quiroga

Facultad de Ciencias Económicas

Universidad Nacional de La Plata 
It always seems impossible

until it's done.

- Nelson Mandela 


\section{Índice}

$\begin{array}{ll}\text { Resumen ejecutivo } & 4\end{array}$

$\begin{array}{ll}\text { Introducción } & 5\end{array}$

$\begin{array}{ll}\text { Presentación del tema de estudio } & 6\end{array}$

Definición de objetivos $\quad 9$

$\begin{array}{ll}\text { Conceptos teóricos } & 10\end{array}$

5.1. Fuentes de información $\quad 10$

5.2. Fundamentos teóricos para el diagnóstico organizacional 11

5.2.1. Business Model Canvas 11

5.2.2. Matriz FODA 13

5.2.3. Matriz de fuerzas competitivas 17

5.3. Fundamentos teóricos para la identificación de necesidades 22

5.3.1. Breve introducción a UX $\quad 22$

5.3.2. Teoría Jobs To Be Done 23

5.3.3. Buenas prácticas para entrevistar personas usuarias 28

5.4. Fundamentos teóricos para la propuesta de intervención 31

5.4.1. Estrategia y posicionamiento 31

5.4.2. Planificación 32

5.4.3. Proceso decisorio $\quad 32$

5.4.4. Gantt 33

5.4.5. Kanban 33

$\begin{array}{ll}\text { Diagnóstico } & 36\end{array}$

6.1. Diagnóstico organizacional 36

6.1.1. Breve reseña del surgimiento 36

6.1.2. Business Model Canvas $\quad 37$

6.1.3. Matriz FODA 42

6.1.4. Matriz de fuerzas competitivas $\quad 45$

6.2. Identificación de las necesidades de las personas usuarias 51

6.3. Alternativas de desarrollo 56

$\begin{array}{ll}\text { Propuesta de intervención } & 62\end{array}$

1) Síntesis del problema 62

2) Objetivo 62

3) Estrategia a implementar 62

4) Descripción de tareas a desarrollar 63 
5) Acciones para evaluar la implementación

Conclusiones

Referencias teóricas

Bibliografía

Fuentes

Anexo

74

1.1. Alojamientos por continente

74

1.2. Alojamientos en América Latina

75

2. Vistas de la plataforma BananaDesk

76

3. Preguntas para la consulta a desarrolladores

80 


\section{Resumen ejecutivo}

El contexto global actual, con su marcada tendencia al uso creciente de dispositivos móviles, hace que tener presencia en este tipo de dispositivos se haya convertido en una exigencia cada vez más fuerte para las organizaciones. En consecuencia, para muchas empresas no tener una versión mobile se vuelve una debilidad.

En este sentido, se tomó el caso BananaDesk, una empresa que ofrece una plataforma de gestión para alojamientos independientes, y se elaboró una propuesta de intervención para resolver el problema de la falta actual de una versión mobile. Para confeccionarla, se consideraron no solo el contexto externo de la empresa, sino también el competitivo y el interno, así como las necesidades de quienes usan la plataforma. Además, se evaluaron distintas alternativas posibles de desarrollo, ya que no hay una única forma de contar con una versión mobile. La propuesta buscó robustecer a la empresa frente a la amenaza de la tendencia mundial mencionada y a sus principales debilidades identificadas, detallando un plan de acción con etapas, tareas y responsables, que pueda llevarse a cabo en el mediano plazo.

Finalmente, se delinearon conclusiones sobre cómo se resolvió la problemática planteada del caso de estudio, así como recomendaciones que puedan ser útiles para otras empresas.

Si bien este trabajo se enfocó en el caso específico de BananaDesk, se espera que pueda servir como guía para otras empresas que también hayan desarrollado sus productos digitales en formato desktop, y requieran adaptarlos para su uso en dispositivos móviles.

Palabras clave: propuesta de intervención, software, plataforma de gestión, dispositivos móviles. 


\section{Introducción}

Este trabajo de aplicación práctica se enfoca en el caso de BananaDesk, una empresa que ofrece una plataforma de gestión o Property Management System (PMS) para alojamientos independientes, y en su necesidad de desarrollar una versión mobile de su plataforma. Esta necesidad responde, por un lado, a la tendencia global al creciente uso de los dispositivos móviles, potenciada por la pandemia de COVID-19; por otro lado, al contexto competitivo de la empresa, donde la ausencia de una versión mobile es una debilidad importante, y lo será cada vez más.

El objetivo último de este trabajo es proponer un plan de acción que pueda resolver la falta actual de una versión mobile de la plataforma, desde una perspectiva que contemple la situación actual de la empresa, las necesidades de las personas usuarias y la mejor alternativa posible para ese desarrollo. Para cumplirlo, se establecieron objetivos específicos referidos a la evaluación de la situación actual de la empresa, la identificación de las necesidades de las personas usuarias y la valoración de distintas alternativas posibles de desarrollo de una versión mobile de la plataforma. Para alcanzar estos objetivos, se recurrió a distintas fuentes de información, tanto primarias como secundarias.

Este trabajo comprende inicialmente una presentación del tema, la definición de los objetivos, la presentación de las fuentes de información consultadas y la explicitación de los fundamentos teóricos contemplados. Luego, haciendo uso de esas fuentes y fundamentos, se confeccionó un diagnóstico que evalúa la situación actual de BananaDesk, tanto internamente como en interacción con su contexto competitivo. También se incluyen los puntos más relevantes para las personas usuarias en torno al uso de la plataforma en dispositivos móviles, precisando quiénes y dónde la usan, qué quieren hacer y qué hacen. Seguidamente, se presenta la evaluación de distintas alternativas posibles de desarrollo de una versión mobile, y la elección de la que mejor se ajusta a BananaDesk.

Teniendo en cuenta todo lo anterior, se confecciona un plan de acción específico para abordar el problema de la ausencia de una versión mobile de la plataforma y para volver visible la nueva implementación para clientes actuales y potenciales. Por último, se presentan las conclusiones y recomendaciones. 


\section{Presentación del tema de estudio}

El presente trabajo de aplicación práctica se enfoca en el caso de BananaDesk, una empresa que ofrece una plataforma de gestión o Property Management System (PMS) para alojamientos independientes, y en su necesidad de desarrollar una versión mobile de su plataforma.

La tendencia internacional que se observa en el creciente uso de los dispositivos móviles no es una novedad. Para el año 2020, el número total de personas usuarias de smartphones había llegado a 3,5 billones, lo que representaba un crecimiento anual (considerando la variación interanual entre 2018 y 2019, y entre 2019 y 2020) del 6.7\%. Se espera que, para el 2023, se llegue a 4,1 billones de personas usuarias, con un crecimiento específico en regiones emergentes (Newzoo, 2020).

Sin embargo, a esta tendencia ya conocida se le suma el efecto de la pandemia de COVID-19. Este hecho dio origen a nuevas necesidades individuales y sociales, que generaron -entre otras cosas - una aceleración en la digitalización de ciertos sectores (como el comercio minorista, la educación, la administración pública, etc.), sobre todo en regiones en las que este proceso todavía no se había dado, o lo hacía muy paulatinamente. En este contexto, con una tendencia que ya existía y que a la vez se vio precipitada, hoy más que nunca es imprescindible, para cualquier tipo de organización, tener presencia en dispositivos móviles.

El turismo, por su parte, se vio fuertemente afectado por la pandemia. Según la Organización Mundial del Turismo (OMT), las llegadas de turismo internacional cayeron un $74 \%$ en el 2020 , causando una pérdida de 1,3 billones de USD de ingresos por turismo internacional y poniendo en riesgo entre 100 y 120 millones de empleos turísticos directos (UNWTO, 2020). Pero la incidencia de la pandemia en el turismo no se dio - ni se está dando- solo en términos cuantitativos, sino también cualitativos, ya que se están modificando las prácticas sociales en torno a los viajes (así como están mutando otras conductas sociales a raíz de la pandemia, como las pautas de consumo de otros bienes y servicios). Aparecen, entonces, turistas que buscan nuevas formas de viajar y de vivir sus experiencias antes, durante y después del viaje. 
Ante estos cambios en la demanda, la oferta turística no puede mantenerse estática, sino que debe acompañarlos. La historia de muchos negocios (como los casos emblemáticos de Blockbuster o Kodak) nos ha demostrado que las empresas que no logran seguir -o mejor: adelantarse a- los cambios en los comportamientos de las personas, corren un alto riesgo de fracasar.

Como se mencionó anteriormente, este trabajo se centrará en el caso de BananaDesk, un Property Management System (PMS) para alojamientos independientes. Esta empresa ofrece una plataforma para la gestión de pequeños alojamientos turísticos en todo el mundo. Es decir, que tiene un modelo Business to business (B2B), ya que quienes contratan el servicio no son los turistas, sino los alojamientos. Sin embargo, por más que los cambios en las nuevas modalidades y preferencias a la hora de viajar de las personas no influyan directamente sobre la empresa, sí lo hacen indirectamente. Por otra parte, la acelerada digitalización presiona a los alojamientos, además de que las mismas personas que trabajan, gerencian y son dueñas de esos establecimientos, están insertas en el mundo que sigue esa misma tendencia.

Es en este contexto en el que la ausencia de una versión de la plataforma que sea compatible con dispositivos móviles (ya que hoy que se encuentra únicamente en formato desktop) como smartphones y tablets, no es solo un problema, sino una debilidad y una desventaja competitiva importante para BananaDesk. Cabe destacar que la plataforma se puede visualizar en dispositivos móviles si se la abre desde el navegador, pero su visibilidad y uso no está optimizado para este tipo de dispositivos.

Aunque todavía no se han reportado casos de clientes que abandonaran la plataforma por esta razón, ni de clientes potenciales que no se hayan podido convertir por no tener una versión mobile, sí llegan quejas de clientes disconformes. Una reconocida frase de Bill Gates dice: "Your most unhappy customers are your greatest source of learning" (traducida: "tus clientes más insatisfechos son tu mejor fuente de aprendizaje"). Prestar atención a lo que las personas usuarias tienen para decir, en términos de quejas, reclamos y sugerencias, es imprescindible para poder conocer sus necesidades y entender dónde y por qué se generan, para así poder desarrollar productos y servicios alineados con ellas. 
Aunque en BananaDesk existe un conocimiento respecto de esta problemática, y de su relativa urgencia, no se han tomado aún acciones concretas para su tratamiento. Por otra parte, se sabe que existen distintas alternativas para desarrollar una versión mobile de la plataforma, cada una con una condición específica respecto de costos, tiempos, dificultad de desarrollo, dificultad de implementación, etc.

El objetivo final de este trabajo es, entonces, llegar a proponer un plan de acción para solucionar este problema, que evalúe cuál sería la mejor alternativa de desarrollo de una versión mobile teniendo en cuenta, por un lado, la situación actual de la empresa y, por el otro, las necesidades de las personas usuarias y la mejor alternativa posible para ese desarrollo.

Se espera que este trabajo sirva como guía para otras empresas que también hayan desarrollado sus productos digitales en formato desktop y requieran adaptarlos para su uso en dispositivos móviles. 


\section{Definición de objetivos}

Los objetivos que se plantean en el presente trabajo son:

- Objetivo general:

- Proponer un plan de acción que pueda resolver la falta actual de una versión mobile de la plataforma, desde una perspectiva que contemple la situación actual de la empresa, las necesidades de las personas usuarias y la mejor alternativa posible para ese desarrollo.

- Objetivos específicos:

- Evaluar la situación actual de la empresa, en base a su diagnóstico organizacional.

- Identificar las necesidades de las personas usuarias en torno al uso de la plataforma en dispositivos móviles.

- Valorar la situación, respecto de criterios establecidos, de distintas alternativas posibles de desarrollo de una versión mobile de la plataforma. 


\section{Conceptos teóricos}

\subsection{Fuentes de información}

Para la elaboración de este trabajo, y el cumplimiento de los objetivos propuestos, se hizo uso de diversas fuentes de información.

Primariamente, para tener una visión más completa de su situación actual, se llevó a cabo una observación participante haciendo uso del rol dentro de la empresa, como Content Writer \& Researcher. Además, se hicieron dos instancias de consulta (mediante formularios de Google Forms enviados por email) con personas que trabajan como desarrolladoras en distintas cooperativas de desarrollo de software y/o empresas. Estas instancias tuvieron como fin poder identificar las distintas alternativas posibles de desarrollo de una versión mobile y poder establecer su posición relativa respecto de distintos criterios.

Por otro lado, se utilizaron fuentes secundarias de información, como fuentes bibliográficas de textos académicos y reportes e informes de organismos internacionales y/o consultoras privadas. También, para la confección del diagnóstico, se utilizó una investigación cualitativa realizada para la empresa BananaDesk, donde se hicieron entrevistas semiestructuradas para conocer el uso que dan las personas usuarias a la plataforma desde dispositivos móviles ${ }^{1}$ y sus necesidades en torno a un eventual desarrollo. Asimismo se referenció un trabajo de aplicación práctica realizado sobre BananaDesk². Por último, se mencionaron métricas y reportes de información con los que cuenta la empresa, a través de la plataforma de analítica Mixpanel ${ }^{3}$.

\footnotetext{
${ }^{1}$ Esa investigación fue realizada entre agosto y octubre de 2020 por Cimatti, María Luisina, que fue Content Writer \& Researcher en BananaDesk, y está autorizada para su uso en este trabajo por Timothy Zenderman (CEO \& Co-founder de BananaDesk) y Ezequiel Moljo (Manager \& Co-founder de BananaDesk). Los datos de las personas entrevistadas y de los alojamientos en los que trabajan no serán divulgados.

${ }^{2}$ Ese trabajo fue realizado en abril de 2021 por Becka, Leandro; Cimatti, María Luisina; Giraldo, José y González Botasi, Sebastián, como trabajo final para la materia Estrategia Empresarial y Gestión de Riesgos de la Maestría en Dirección de Empresas, Facultad de Ciencias Económicas de la Universidad Nacional de La Plata.

${ }^{3}$ Autorizados para su mención en este trabajo por Timothy Zenderman (CEO \& Co-founder de BananaDesk) y Ezequiel Moljo (Manager \& Co-founder de BananaDesk).
} 


\subsection{Fundamentos teóricos para el diagnóstico organizacional}

A continuación se presentan los fundamentos teóricos de las herramientas empleadas para realizar el diagnóstico organizacional.

\subsubsection{Business Model Canvas}

Para la descripción del modelo de negocio de BananaDesk, se utilizará la herramienta conocida como Business Model Canvas, según la presentaron Alexander Osterwalder e Yves Pigneur en el emblemático libro Business Model Generation, publicado por primera vez en el año $2010^{4}$. A pesar de que existen distintas plantillas para reflejar aspectos más específicos de los negocios (como, por ejemplo, el Value Proposition Canvas o el Empathy Map Canvas), se ha elegido hacer uso de esta herramienta en su formato inicial, por ser la más ampliamente difundida para mostrar brevemente modelos de negocio. Posteriormente se detallarán brevemente aspectos relevantes de cada uno de los apartados del Business Model Canvas.

Las secciones en las que se divide esta plantilla son:

\begin{tabular}{|l|l|l|l|l|}
\hline $\begin{array}{l}\text { Asociaciones } \\
\text { Clave }\end{array}$ & Actividades Clave & $\begin{array}{l}\text { Propuestas de } \\
\text { valor }\end{array}$ & $\begin{array}{l}\text { Relaciones con } \\
\text { clientes }\end{array}$ & $\begin{array}{l}\text { Segmentos de } \\
\text { mercado }\end{array}$ \\
& Recursos Clave & & Canales & \\
\cline { 3 - 5 } & & & \\
\hline Estructura de costos & Fuentes de ingresos & \\
& &
\end{tabular}

Fuente: Osterwalder \& Pigneur (2010, p. 24)

\footnotetext{
${ }^{4}$ En la versión en español del libro, Generación de modelos de negocio, publicada en el año 2011, se llama a la herramienta "lienzo del modelo de negocio".

${ }^{5}$ Esta y las demás tablas y matrices de este apartado han sido modificadas respecto de su versión original, que se encuentra en la fuente citada, para que su estilo acompañe el del documento de este trabajo. La versión en español de los nombres de las secciones del Business Model Canvas utilizada en este trabajo es la presentada en la traducción del libro original, referida en la nota anterior.
} 
- Segmentos de mercado (Customer Segments): son aquellos segmentos de la demanda que conforman el objetivo (target) del negocio. Es para satisfacer las necesidades de las personas que se encuentren dentro de esos segmentos, que se ofrece un determinado producto o servicio.

- Propuestas de valor (Value Propositions): son aquellos aspectos del producto o servicio que lo diferencian de los demás, haciendo que una persona se decida por lo que ofrece un negocio y no otro. Están íntimamente relacionados con las necesidades de las personas, ya que son el cómo un producto o servicio las atiende y resuelve. No necesariamente las propuestas de valor tienen que ser innovadoras, muchas veces un negocio ofrece, mediante un producto, una solución a un problema que otros negocios ya ofrecen. Sin embargo, una propuesta de valor puede centrarse en una solución que, respecto de otras, sea más eficiente, mejor diseñada, más cómoda, menos costosa, más accesible, menos riesgosa, etc.

- Canales (Channels): son los canales que permiten que el negocio se relacione con sus clientes. Los canales pueden ser tanto de comunicación, como de distribución y venta. Estos canales existen durante toda la relación que un negocio establece con las personas, desde que se da a conocer, hasta que se establece un intercambio comercial, y después de éste, en la posventa.

- Relaciones con clientes (Customer Relationships): este punto se refiere a las formas que toma la relación de un negocio con sus clientes. En el modelo presentado por Osterwalder (2010), se presentan como opciones la asistencia personal (exclusiva o no), el autoservicio, los servicios automáticos, las comunidades y la creación colectiva ${ }^{6}$.

- Fuentes de ingreso (Revenue Streams): es la forma en la que un negocio monetiza, es decir, cómo logra generar ingresos en términos financieros. Existen distintas alternativas en este punto, como pagos por suscripción, modelos freemium, publicidades, franquicias, etc. En esta sección, también se hace referencia a los precios, es decir, a plantear la pregunta de cuánto están dispuestas a pagar las personas por el producto o servicio del negocio.

\footnotetext{
${ }^{6}$ Muchas empresas de los últimos años hacen uso de este último tipo de relación, invitando a las personas usuarias y/o clientes a "participar" activamente, co-creando contenido que genera, a su vez, valor para otras personas y para el negocio.
} 
- Recursos clave (Key Sources): son los recursos (o activos) que permiten al negocio llevar a cabo su propuesta de valor. Pueden ser propios o no, y pueden ser tanto físicos, como económicos, intelectuales o humanos (Osterwalder \& Pigneur, 2010). Actualmente, existe una tendencia a declarar al capital humano como aquel más determinante para el éxito de un negocio.

- Actividades clave (Key Activities): son aquellas actividades que son imprescindibles para hacer que el negocio funcione. Estas actividades están fuertemente relacionadas con los recursos clave (que permiten que se lleven a cabo y, además, las implementan) y con las propuestas de valor. No debe pensarse a las actividades clave únicamente como la producción de un bien o servicio, sino también como la resolución de problemas que éste ofrece.

- Asociaciones clave (Key Partnerships): las asociaciones clave hacen referencia a las redes que permiten el funcionamiento del negocio. Estas asociaciones se dan con las personas de los segmentos objetivo, con competidores (y/o coopetidores ${ }^{7}$ ), con proveedores, con inversores, etc.

- Estructura de costos (Cost Structure): la estructura de costos busca mostrar cuáles son los costos en los que incurre el negocio para llevar adelante sus actividades clave, que le permiten ofrecer su producto o servicio con su mencionada propuesta de valor. Deben considerarse separadamente los costos fijos y variables. También deben tenerse en cuenta otros aspectos, como si el negocio se encuentra dentro de una economía de escala, o si su propuesta de valor viene dada por un bajo precio.

\subsubsection{Matriz FODA}

Como una de las herramientas para analizar el entorno en el que se encuentra BananaDesk, se utilizará la matriz FODA. Esta forma de presentar los puntos fuertes y débiles, tanto del contexto externo como interno de la empresa, tuvo su origen entre 1960 y

\footnotetext{
${ }^{7}$ La coopetición se define como una cooperación y competición simultánea entre competidores. La confianza y los intereses en común conforman la base de la cooperación efectiva. La cooperación entre competidores no significa que se debilite la rivalidad entre ellos (traducción propia de Cygler, Sroka, Solesvik \& Dębkowska, 2018, p. 2).
} 
$1970^{8}$ (Otero \& Gache, 2006), y ha sido ampliamente utilizada desde ese entonces hasta el presente.

La matriz FODA (también conocida como matriz DAFO, o SWOT, por sus siglas en inglés) se divide en los cuatro elementos siguientes:

- Fortalezas (Strengths): las fortalezas son uno de los dos cuadrantes de la matriz que se refiere al análisis interno. Una fortaleza es toda acción o función que una organización realiza de manera correcta, así como los recursos que considere como valiosos, sus capacidades competitivas, habilidades del personal, etc. También entran en este cuadrante elementos como: el reconocimiento de la marca, el acceso a economías de escala, las capacidades de producción, el acceso a ciertas tecnologías, las capacidades directivas, flexibilidad y habilidades para la innovación, etc (Talancón, 2007).

- Debilidades (Weaknesses): las debilidades se corresponden con el segundo cuadrante de la matriz que se refiere al análisis interno. Una debilidad es todo aspecto que vuelve vulnerable a la organización. También se considera como debilidad toda acción o función que una organización realice deficiente o ineficientemente. Entran en este cuadrante aspectos como: una dirección estratégica poco definida, atrasos en investigación y desarrollo, incapacidad de financiamiento, y una mala o débil imagen, etc (Talancón, 2007).

- Oportunidades (Opportunities): las oportunidades son uno de los dos cuadrantes de la matriz que se refiere al análisis externo. Una oportunidad representa un elemento potencial de crecimiento o mejora, de carácter no controlable para una organización, que le permite direccionar algunas de sus estrategias. Se encuentran dentro de este cuadrante elementos como: el ingreso en nuevos mercados, la aparición de nuevos segmentos de demanda o de nuevas tecnologías, la eliminación de barreras comerciales, etc (Talancón, 2007).

\footnotetext{
${ }^{8}$ Inicialmente, se presentó un modelo denominado SOFT (Satisfactory, Opportunity, Fault y Threat), que había sido elaborado por un grupo de la Universidad de Stanford, liderado por el Dr. Otis Benepe. Sin embargo, ese nombre posteriormente se modificó por el actual, en el año 1964. La matriz, tal como se la conoce hoy, existe desde el 1973, y fue utilizada por primera vez para lograr la fusión de los negocios de las empresas CWS y J. W. French Ltd (Otero \& Gache, 2006).
} 
- Amenazas (Threats): las amenazas se corresponden con el segundo cuadrante de la matriz que se refiere al análisis externo. Son aquellos elementos del entorno, de carácter no controlable para una organización, que le crean dificultades y problemas potenciales. También es sumamente importante tenerlas en cuenta a la hora de delinear estrategias. Entran en este cuadrante aspectos como: la entrada de nuevos competidores, ciclos económicos desfavorables, una ralentización del crecimiento del mercado, un cambio en las necesidades y/o gustos de clientes, un crecimiento en el poder de negociación de compradores o proveedores, etc (Talancón, 2007).

Esta matriz, también puede pensarse como una "matriz porterizada" (Otero \& Gache, 2006), ya que de la combinación de los cuatro elementos mencionados, surgiría una descripción del plano competitivo en el que se encuentra la empresa.

En cuanto a su posición competitiva, se presentan las siguientes dos combinaciones:

- Ventajas competitivas (Fortalezas + Oportunidades): éstas se dan cuando, gracias a las fortalezas de una organización, se pueden potenciar o aprovechar las oportunidades del entorno de una forma más eficiente que aquella en que puedan hacerlo sus competidores.

- Desventajas competitivas (Debilidades + Amenazas): contrariamente a las ventajas competitivas, las desventajas se dan cuando, frente a los mismos aspectos negativos del entorno, una organización es más vulnerable y, por eso, se ve más afectada que sus competidores.

En cuanto a las variables del entorno, se presentan las siguientes dos combinaciones:

- Variables de control (Debilidades + Fortalezas): la combinación de las variables sobre las que tiene control una organización deben ser claramente conocidas y consideradas por ésta, ya que son las únicas sobre las que puede accionar en concreto, para potenciarlas o mejorarlas. 
- Variables no controladas (Amenazas + Oportunidades): la consideración en conjunto de las variables no controladas es de gran importancia para poder delinear las mejores estrategias posibles para una organización que, teniendo en cuenta las variables de control, "tiendan a aumentar las oportunidades y a disminuir las amenazas" (Otero \& Gache, 2006, p. 9).

Un análisis adicional que se puede hacer en base a la matriz FODA es la elaboración de las matrices de evaluación de los factores internos (o MEFI) y externos (o MEFE):

- Matriz de Evaluación de los Factores Internos (MEFI): esta matriz busca poder evaluar los factores internos (fortalezas y debilidades), para posteriormente poder analizarlos y compararlos (entre sí o en un análisis comparativo entre proyectos, negocios, etc.). La elaboración de la MEFI consiste en:

1. Listar las fortalezas y debilidades.

2. Adjudicar a cada aspecto un peso relativo, teniendo en cuenta que el resultado final de la suma de todos estos aspectos del análisis interno debe ser de 1 o de un $100 \%$.

3. Adjudicar a cada aspecto una calificación del 1 al 4 , teniendo en cuenta que 1 será considerada como la puntuación menos importante y 4 como la más importante.

4. Multiplicar, para cada aspecto, su calificación por su peso relativo.

5. Sumar los valores de los aspectos, tanto por el factor interno de que se trate, como el valor total de todos los aspectos de ambos factores.

6. Comparar el puntaje obtenido en ambos factores: si el puntaje obtenido en las fortalezas es más alto que el obtenido por las debilidades, entonces las fuerzas internas serán favorables para la organización. Caso contrario, se considerará que las fuerzas internas son desfavorables para la organización (Talancón, 2007).

- Matriz de Evaluación de los Factores Externos (MEFE): esta matriz busca poder evaluar los factores externos (oportunidades y amenazas), para posteriormente 
poder analizarlos y compararlos. Su confección es similar a la de la MEFI, pero deben considerarse, calificarse y ponderarse los aspectos correspondientes al entorno.

Existe una única diferencia en su confección, que reside en la adjudicación de la calificación. En la MEFE, de acuerdo con Talancón (2007, p. 118), se debe:

Ponderar con una calificación de 1 a 4 cada uno de los factores considerados determinantes para el éxito, con el propósito de evaluar si las estrategias actuales de la empresa son realmente eficaces; 4 es una respuesta considerada superior, 3 es superior a la media, 2 una respuesta de término medio y 1 una respuesta mala.

Si, luego de confeccionar la matriz y de realizar los cálculos correspondientes, el puntaje obtenido por la suma de los aspectos del factor externo de las oportunidades es mayor que el obtenido por el de las amenazas, entonces la organización estará dentro de un contexto que le es favorable. Caso contrario, se considerará que el contexto es desfavorable para la organización (Talancón, 2007).

Además, el total de la suma de los aspectos de ambos factores puede compararse con la puntuación mencionada (de 1 a 4). Por ejemplo, un total ponderado de 2.5 determinaría que una organización se encontraría "por debajo de la media en cuanto al esfuerzo por seguir estrategias que permitan aprovechar las oportunidades externas y evitar las amenazas externas" (Talancón, 2007, p. 119).

\subsubsection{Matriz de fuerzas competitivas}

Para completar el análisis del contexto se hará uso de la matriz de fuerzas competitivas elaborada por Michael Porter que, en sus palabras, "puede ayudar a una empresa a comprender la estructura del sector en el cual compite y elaborar una posición que sea más rentable y menos vulnerable a los ataques" (Porter, 2008a, p. 1).

Las fuerzas que menciona Porter son las siguientes: 


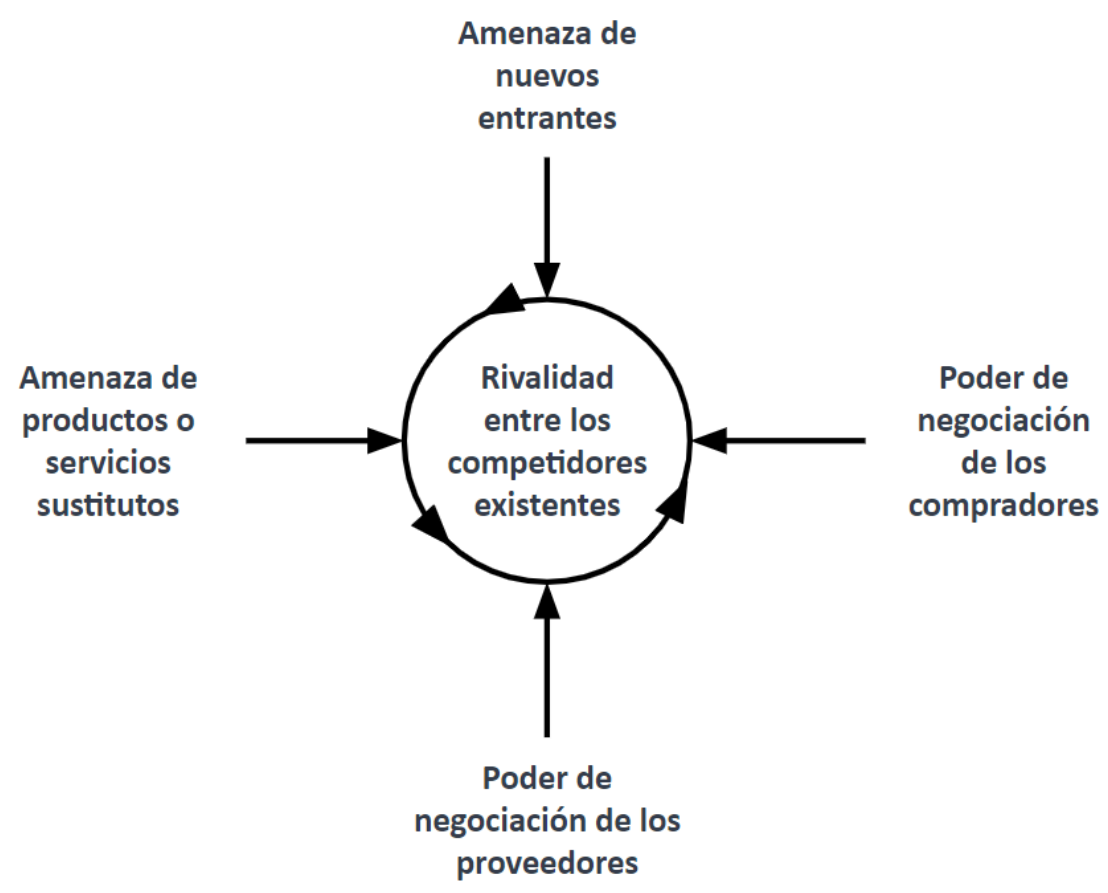

Fuente: Porter (2008a, p. 2).

- Amenaza de nuevos entrantes: la amenaza de nuevos entrantes constituye el riesgo de que la rentabilidad del sector baje. Sin embargo, la posibilidad de que verdaderamente entren en escena nuevos competidores dependerá de las barreras de entrada del sector. Estas barreras pueden ser más altas o bajas dependiendo, por ejemplo, de los siguientes factores:

- La existencia de economías de escala, esto es, cuando una empresa minimiza sus costos por tener un mayor volumen de operaciones, ya que se reducen los costos por unidad, al distribuirlos entre más unidades producidas.

- La existencia de "efectos de red" (Porter, 2008a, p. 3), es decir, cuando una empresa cuenta con clientes potenciales cuya disposición a pagar aumenta cuando más personas también usan el producto o servicio que se ofrece.

- Qué tan costoso (en términos financieros, pero también de esfuerzo, tiempo, etc.) es, para quien compra, dejar de comprarle un producto o servicio a una empresa y pasarse a otra. 
- Qué tanto capital se requiere, principalmente, para la inversión inicial necesaria para ingresar al sector.

- La existencia de ventajas (de costos o de calidad) de la que gozan los actores ya establecidos y que se deben, por ejemplo, a factores como tecnología adquirida o acceso preferencial a las mejores fuentes de materias primas, identidades de marcas establecidas o experiencia acumulada.

- Qué tan difícil es acceder a los canales de distribución del sector que sean necesarios para que la empresa pueda ofrecer sus productos o servicios en el mercado.

- Políticas gubernamentales sobre el sector que, si existieran, podrían obstaculizar u obstruir (o, por el contrario, favorecer o promover) el ingreso de nuevos entrantes.

Por otra parte, deben considerarse las represalias esperadas por los nuevos entrantes, por parte de los actores ya establecidos en el sector, ya que pueden determinar que decidan entrar o no.

- Amenaza de productos o servicios sustitutos: la amenaza de sustitutos existe cuando hay otros productos o servicios que pueden cumplir la misma función que el que ofrece una determinada empresa. La amenaza puede ser más alta o baja, dependiendo de factores como el precio del producto o servicio, o el costo por sustitución que sufrirán quienes lo usen ${ }^{9}$.

- Poder de negociación de compradores: el poder de negociación de compradores varía dependiendo de, por ejemplo:

- Su número y tamaño, ya que si son pocos clientes que adquieren grandes volúmenes de algún producto, su poder de negociación será mayor que el de muchos clientes que compran pocas unidades.

- La diferenciación del producto o servicio por el que pagan, ya que si éste está estandarizado, podrán siempre encontrar uno equivalente.

\footnotetext{
9 En este punto, teniendo en cuenta la teoría de Jobs To Be Done (Klement, 2018) que se presentará en el siguiente apartado de este trabajo, se debe tener en cuenta que un producto o servicio sustituto no tiene por qué ser un mismo producto o servicio ofertado por un competidor. Un sustituto puede ser otro tipo de producto o servicio, de otro sector, que haya sido pensado para cumplir otras necesidades, pero cuyas funciones puedan usarse de alguna forma para cumplir las necesidades de las personas en torno al producto o servicio que sustituirán.
} 
A su vez, hay segmentos compradores que son más sensibles que otros a los precios. Esta sensibilidad responderá a:

- El porcentaje que representa la compra del producto o servicio respecto de sus ingresos.

- Qué tan relevante es la calidad de un producto o servicio para quien lo compra, ya que si no lo es mucho, no estará dispuesto a pagar un precio alto.

- Poder de negociación de proveedores: el poder de negociación con que cuentan las empresas proveedoras dependerá de, por ejemplo:

- La concentración del sector al cual provee, es decir, si, por ejemplo, le vende a un monopolio u oligopolio.

- Qué tanto depende su sustento de las ventas que hace en determinado sector. Si el sector no es relevante, se buscará maximizar las utilidades sin recaudos. Si, por el contrario, un sector representa un alto porcentaje del volumen de utilidades de un proveedor, éste querrá protegerlo mediante, por ejemplo, buenos precios.

- Qué tan costoso es, para una empresa, cambiar de proveedor. Este punto es similar al que se refiere a qué tan costoso es, para quien compra, cambiar de producto o servicio, pero ocurre en otro lugar de la cadena.

- La diferenciación de los productos que proveen.

- La ausencia de proveedores sustitutos.

- Rivalidad entre competidores existentes: la rivalidad entre competidores, que se da bajo las tradicionales formas de lanzamiento de nuevos productos o servicios, campañas publicitarias, precios, desarrollo de tecnologías, etc., será más o menos intensa dependiendo de, por ejemplo:

- La cantidad o tamaño de empresas competidoras, por ejemplo, habrá una rivalidad más intensa cuanto más competidores haya, y cuanto más similares sean en potencia.

- La velocidad de crecimiento del sector, que determinará qué tanto deberá lucharse por la participación en el mercado. 
- Las barreras de salida que mantienen a los participantes dentro del sector, quizá aunque éste no les sea rentable, por una dificultad de salirse, si las barreras son altas.

- La aspiración de las empresas competidoras a convertirse en líderes del mercado.

- La diferenciación de los productos que ofrecen.

Debe considerarse que la rivalidad puede ser positiva, e incluso "puede incrementar la rentabilidad promedio de un sector, cuando las empresas competidoras buscan satisfacer las necesidades de distintos segmentos de consumidores con distintas combinaciones de precios, productos, servicios, prestaciones o identidades de marcas" (Porter, 2008a, p. 8). Sin embargo, la rivalidad será negativa para la rentabilidad de un sector cuanto más se centre en el precio.

Finalmente, Porter (2008a, p. 8) destaca la diferencia entre fuerzas (las mencionadas) y factores (como productos y servicios complementarios, reglamentaciones, nuevas tecnologías y crecimiento del sector que, según sean favorables o desfavorables, se corresponden con los factores del ambiente externo mencionados en el apartado anterior: oportunidades o amenazas).

La forma que se utilizará, en este trabajo, para evaluar las fuerzas competitivas será identificar, para cada fuerza, las variables relevantes y puntuándolas del 1 al 5 . Luego se sumarán los puntajes y, según rangos establecidos previamente ${ }^{10}$, se determinará cómo influye cada fuerza sobre BananaDesk.

\footnotetext{
${ }^{10}$ Se establecerá siempre que se estará en un rango "bajo" cuando la suma de los valores sea menor o igual a la cantidad de variables por dos; se estará en un rango "medio" cuando la suma de los valores se encuentre entre la cantidad de variables por dos y la cantidad de variables por cuatro; se estará en un rango "alto" cuando la suma de los valores sea mayor o igual a la cantidad de variables por cuatro. Es decir que, si una fuerza contempla cinco variables relevantes, se estará en el rango "bajo" cuando la puntuación sea menor o igual a diez puntos; se estará en el rango "medio" cuando la puntuación se encuentre entre diez y veinte; se estará en el rango "alto" cuando la puntuación sea mayor o igual a veinte puntos.
} 


\subsection{Fundamentos teóricos para la identificación de necesidades}

A continuación se presentan los fundamentos teóricos de la perspectiva con la que, en BananaDesk, se realizan todas las entrevistas a personas usuarias.

\subsubsection{Breve introducción a UX}

Previo a avanzar con los fundamentos teóricos relacionados específicamente con las entrevistas que se reseñan en este trabajo, existe un concepto que obligatoriamente debe mencionarse, para poder entender el propósito central con el que se entrevista a las personas usuarias.

El término UX, del inglés User Experience, experiencia de usuario o de personas usuarias, fue acuñado por Donald Norman ${ }^{11}$ en los años '90. Aunque existen múltiples definiciones del término, en este trabajo se considera la de Norman (s.f.), que define al UX como aquella experiencia que: "engloba todos los aspectos de la interacción de los usuarios finales con la compañía, sus servicios y sus productos". En este sentido, se entiende a la experiencia de las personas como un todo: no solo considera la experiencia de uso de un producto o servicio, sino también la experiencia previa y posterior que tienen las personas, y cómo interactúan con las empresas. Esta visión holística de las experiencias, se alinea fuertemente con la teoría y principios que se enuncian en el apartado siguiente.

Con el correr de los años, UX se ha ido transformado paulatinamente en una disciplina ( $y$ en muchas empresas, mayormente tecnológicas, en un área con gerencia propia) que comprende, a su vez, especialidades como UX Design, UX Content, UX Writing y UX Research. En los equipos UX, todas estas especialidades trabajan articuladamente, ya que tanto el diseño de las experiencias y de su contenido, y la investigación con personas usuarias, no son separables entre sí.

\footnotetext{
${ }^{11}$ Donald Norman, ingeniero eléctrico y psicólogo, fue el autor del emblemático libro "The Design of Everyday Things" (publicado por primera vez en 1988, con el nombre "The Psychology of Everyday Things"). Conocido por ser el "padre del UX", acuñó el término cuando trabajaba en Apple, en los años '90. Junto con Jakob Nielsen, ingeniero y diseñador de interfaces pensadas para personas usuarias, conocido por ser el "padre de la usabilidad" (y ampliamente reconocido por haber enunciado las "10 Usability Heuristics"), crearon la firma más reconocida en consultoría e investigación en UX a nivel global: Norman Nielsen Group (esta y más información puede verse en el sitio web oficial de NN/group: https://www.nngroup.com/).
} 


\subsubsection{Teoría Jobs To Be Done}

Las investigaciones que se llevan a cabo en BananaDesk se hacen desde la perspectiva de la teoría Jobs To Be Done $(\mathrm{JTBD})^{12}$, con la que también se ha pensado la creación de la plataforma y de todas sus funcionalidades.

La premisa central desde la que se desarrolla esta teoría es la del Self-Betterment, o mejoramiento personal, que postula que los seres humanos innovamos incansablemente en el uso que le damos a nuestro entorno: para imaginar mejores escenarios, cambiar situaciones existentes por otras que prefiramos e/o imaginar cómo nos gustaría que siga nuestra vida. Es decir, que los seres humanos siempre tratamos de mejorar diferentes aspectos de nuestras vidas a través de distintas formas (Klement, 2015).

Tradicionalmente, desde los negocios, se han estudiado las necesidades y expectativas de quienes compran, en lugar de crear nuevos sistemas que ayuden a las personas a progresar. A menudo, cuando se cree que se están estudiando necesidades de clientes, en realidad se está relevando qué es lo que las personas dicen ${ }^{13}$ que no les gusta de un determinado producto ${ }^{14}$, o qué es lo que esperan de él: "no podemos construir los productos de mañana si nos limitamos a las necesidades y expectativas asociadas con los productos de hoy. En cambio, deberíamos enfocarnos en lo que nunca cambia para quienes compran: su deseo de progresar" (Klement, 2015, p. 19; traducción propia).

Para cerrar la idea central, y enunciar los principios de la teoría, cabe señalar que un JTBD muestra en qué sentido una persona cambia o desea cambiar para progresar. La teoría de los Jobs (trabajos) de las personas, postula que los mercados crecen y se transforman siempre que las personas tienen un trabajo que hacer (en inglés, un Job To Be Done) y

\footnotetext{
12 Esta teoría deriva de los Customer Jobs, cuyos principios provienen de la estadística, economía, psicología, y otras disciplinas que han evolucionado en los últimos 80 años, desde que el economista Joseph Schumpeter (a principios de los años '40) hablara de la "destrucción creativa" (en inglés: Creative Destruction): el primer concepto que comenzó a dar forma a la idea de los Customer Jobs (según la presentación que Klement (2015) hace de las ideas que influenciaron a los Customer Jobs).

${ }^{13}$ En este punto, se debe tener en cuenta que a veces lo que piden las personas es cumplir determinadas acciones, porque eso es lo que creen necesitar. La conocida idea de la "miopía del marketing" de Theodore Levitt, que ya en los años '60 postuló que "la gente no compra un producto, compra soluciones", postulaba que, cuando alguien compra un taladro, en realidad compra agujeros en la pared. Sin embargo, Donald Norman (creador del Activity-Centered Design y autor del conocido libro The Design of Everyday Things) plantea que quizá el razonamiento de Levitt quedó truncado, ya que "cuando te das cuenta de que en realidad no quieren el taladro, te das cuenta de que quizá tampoco quieren realmente el agujero: quieren poner estantes para libros. ¿Por qué no desarrollar métodos que no requieran agujeros? 0 quizá libros que no requieran estantes. (Sí, ya sé: libros electrónicos, e-books.)" (traducción propia de Donald Norman, citado en Klement, 2015 , p. 36).

${ }^{14}$ En este apartado se utilizará la palabra "producto" para hacer referencia a un bien o servicio indistintamente.
} 
compran un producto para lograrlo (tener el trabajo hecho o, en inglés, get the Job Done) (Klement, 2015).

Los principios que enuncia esta teoría son los siguientes:

- Las personas tienen Jobs, las cosas no: los productos no tienen vidas para mejorar. No debe pensarse "mi producto tiene X, Job To Be Done", sino que los productos pueden ser posibles soluciones a un JTBD que tenga una persona.

- La competición está definida en la mente de las personas, y éstas usan el progreso como criterio: "no definen ni restringen la competición en base a la funcionalidad o apariencia física de un producto. En cambio, usan lo que sea que las ayude a progresar frente a un JTBD" (Klement, 2015, p. 44; traducción propia).

- Cuando se empieza a usar una solución para un Job, se deja de usar otra: el uso de las soluciones es mutuamente excluyente, las personas prefieren solo una solución específica para un determinado trabajo en un determinado momento.

- Las oportunidades de innovación existen cuando las personas exhiben comportamientos compensatorios: las situaciones en las que usan productos para soluciones para las que no fueron creados "representan oportunidades para innovar en un producto o reparar uno existente" (Klement, 2015, p. 44; traducción propia).

- Se debe favorecer el progreso sobre resultados y metas: cumplir una meta hoy no es tan importante como volverse mejores en el futuro, esto también pasa con quienes compran: para saber si un producto les gusta o no, no consideran solo el resultado, sino todo el proceso de su uso. "Necesitan sentirse exitosos en cada punto de contacto entre ellos mismos y tu negocio, no solamente al final, cuando ocurre el resultado de la acción" (Klement, 2015, p. 45; traducción propia).

- El progreso define el valor, la comparación lo revela: se puede comprender cuál es verdaderamente el valor que las personas obtienen de un producto cuando éstas miden el progreso que les genera en un determinado contexto. Sin embargo, la revelación de este valor se evidencia en comparación con el progreso que les otorgaría otro producto en ese mismo contexto. 


\section{- Las soluciones a los Jobs brindan valor más allá del momento de uso:}

[U]na solución puede ser funcional únicamente en el momento, pero su valor para la persona se da en contextos más allá de ese momento. Un producto debería ser diseñado con un entendimiento de cómo mejora la vida de quienes lo compran, no solamente de cómo ofrece valor en el momento (Klement, 2015, p. 46; traducción propia).

- Los productores, consumidores, soluciones y Jobs deben considerarse como elementos de un sistema, que trabajan en conjunto para evolucionar los mercados: el valor no es una parte del sistema ni pertenece solo a uno de sus elementos, sino que resulta de qué tan bien funcionen los elementos del sistema. Por otra parte, entender que un correcto funcionamiento de todos los elementos que componen al sistema es lo que hace evolucionar a los mercados, permite también ver por qué algunos mercados no evolucionan.

Para finalizar la presentación de JTBD, solo resta mencionar y describir brevemente las Fuerzas del Progreso (Forces of Progress), que son aquellas que generan o reducen la demanda. Estas fuerzas son emocionales, actúan en sentidos opuestos y van dando forma a la demanda de un producto. Las personas experimentan una combinación de estas fuerzas al momento de buscar, elegir y usar un producto.

Las Fuerzas del Progreso son principalmente cuatro, aunque estas a su vez se dividen en dos. De estas cuatro fuerzas principales, dos actúan a favor de la demanda, es decir, generándola; las otras dos actúan en contra de la demanda, es decir, reduciéndola. Generalmente, el desarrollo de productos se centra en entender las fuerzas creadoras de demanda, cuando es igualmente (o más) importante conocer las destructoras. 


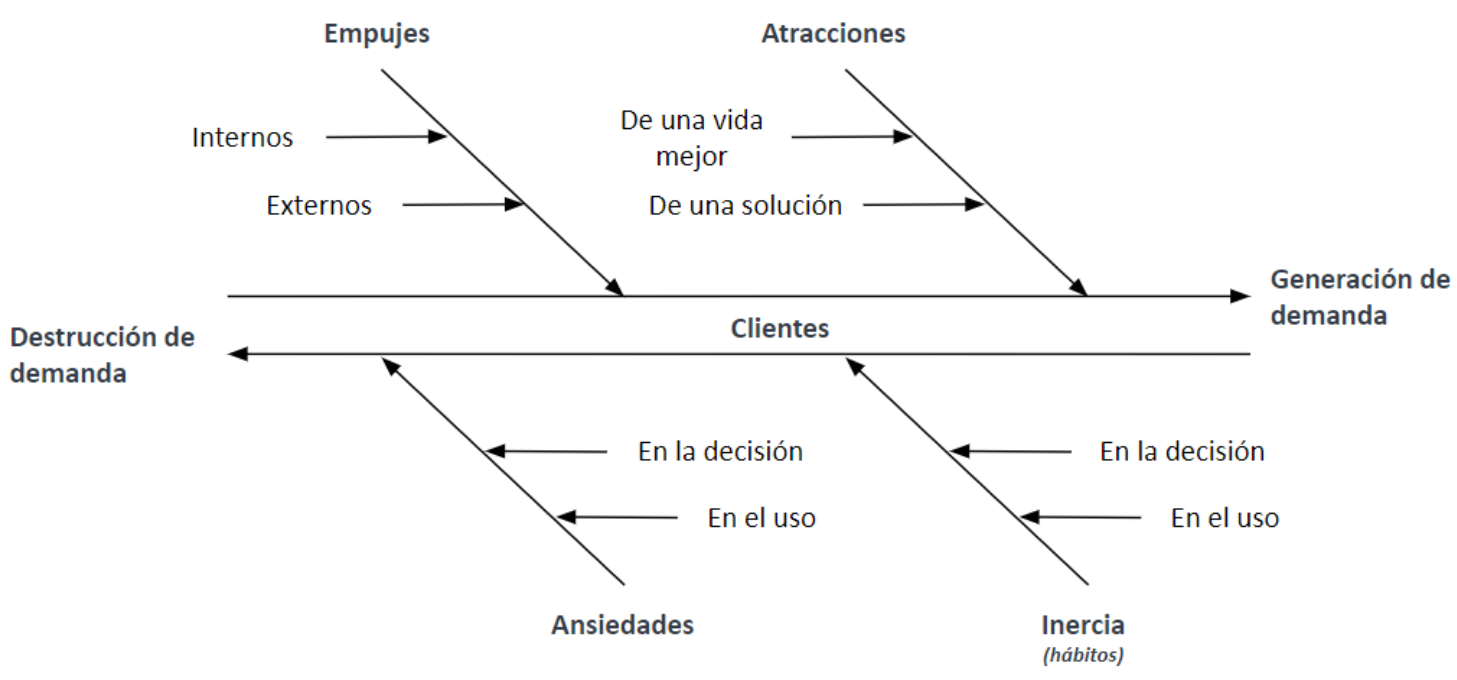

Fuente: Klement (2015, p. 89; traducción propia).

Las fuerzas que generan demanda son las siguientes:

- Empuje (Push): agrupa aquellas fuerzas que empujan a las personas a querer o necesitar mejorar sus vidas.

- Empujes externos (External pushes): cambios en el contexto de vida de una persona, que la obliga a tener que salir de su habitualidad y buscar nuevas soluciones. No necesariamente tienen que ser cambios en variables no controlables, por ejemplo, Klement (2015) ejemplifica el caso de una pareja que tuvo un bebé y debe comprar una silla para el auto.

○ Empujes internos (Internal pushes): son motivaciones puramente internas que llevan a las personas a querer cambiar, ser mejores en algo, resolver algo más fácilmente, etc. En síntesis, un deseo de progresar en algún aspecto.

- Atracción (Pull): son aquellas fuerzas que atraen a las personas hacia un cambio, no por obligación, sino porque les interesa la idea de cambiar (para mejor) alguna situación en sus vidas.

- Atracción de una vida mejor (The pull for a better life): en palabras de Klement (2015, p. 85; traducción propia): 
[L]as personas no compran productos solamente para tenerlos o usarlos; los compran para contribuir a hacer sus vidas mejores (es decir, a progresar). Cuando tienen el producto adecuado para su problema, son capaces de hacer cosas que no podían hacer antes. La idea de una vida mejor es lo que las tracciona a actuar.

- Atracción de una solución (The pull toward a solution): la idea de encontrar una solución a un problema, y progresar, es lo que hace que una persona comience a buscarla y, finalmente, encuentre alguna y la implemente. Pero, ¿qué hace que una persona elija una determinada solución para un problema y no otra? El contexto y la interacción con las demás fuerzas. Por eso es que coexisten productos que entregan distintas soluciones a los mismos problemas, simplemente porque las personas, frente a los mismos problemas, no siempre toman las mismas decisiones.

Las fuerzas que reducen demanda, por su parte, deben considerarse como competidores: "no importa si una persona se queda con su forma actual de resolver problemas, o compra la solución de un competidor: la perdiste como cliente" (Klement, 2015, p. 89; traducción propia). Estas fuerzas son las siguientes:

- Ansiedad (Anxiety): son aquellas fuerzas que inhiben a las personas y hacen que prefieran quedarse en su situación actual, en lugar de buscar una mejora.

- Ansiedad en la decisión (Anxiety-in-choice): se da únicamente cuando un determinado producto no se ha usado nunca antes, y radica en la incertidumbre sobre si ese producto podrá ayudar a la persona a progresar -o no- y en cómo lo hará.

- Ansiedad en el uso (Anxiety-in-use): se da cuando ya se sabe que un determinado producto puede ayudar a una persona a progresar, pero algunas de sus características generan inseguridades a la hora de usarlo. Este tipo de fuerza suele aparecer cuando se ha usado un producto en una determinada situación y contexto, y no se sabe si servirá de igual forma en otra situación y contexto. 
- Inercia ${ }^{15}$ (Inertia): agrupa aquellas fuerzas que hacen que, si las personas no realizan proactivamente un cambio, todo siga igual.

- Hábitos en la decisión (Habits-in-choice): esta fuerza existe en el momento de decidir si cambiar de un producto - o solución- a otro. Entra en juego, en este momento, uno de los puntos mencionados en el apartado de las fuerzas competitivas de Porter cuando, dentro de la amenaza de nuevos entrantes, se destaca qué tan costoso es para una persona, dejar de comprarle un producto a una empresa y comprarle a otra. Desde la perspectiva de JTBD, ese costo no es un costo en términos financieros, sino de esfuerzo en términos principalmente emocionales.

○ Hábitos en el uso (Habits-in-use): esta fuerza aparece cuando una persona que adoptó un nuevo producto -o solución- vuelve a usar el producto anterior, no porque sea mejor, sino porque es más fácil mantener hábitos viejos que aprender e internalizar otros nuevos.

\subsubsection{Buenas prácticas para entrevistar personas usuarias}

A la hora de hacer investigaciones cualitativas con personas usuarias, en BananaDesk se realizan entrevistas que consideran los principios presentados por Steve Portigal ${ }^{16}$ en su reconocido libro Interviewing users: How to uncover compelling insights. En el sexto capítulo de este libro ("How to ask questions?") se presentan algunos puntos clave a tener en cuenta a la hora de entrevistar personas usuarias:

- No dejar que la guía de la entrevista se convierta en un guión; debe ser solo para tener una referencia ya que, de lo contrario, podría perderse información valiosa por saltar de una pregunta a otra, sin considerar los caminos alternativos que puede tomar una conversación y que puede resultar útil explorar. Se debe hacer una pregunta y luego pensar en preguntas de seguimiento, cuando el curso que toma la conversación sea de interés.

\footnotetext{
${ }^{15}$ Según el diccionario de la Real Academia Española, inercia es la "propiedad de los cuerpos de mantener su estado de reposo o movimiento si no es por la acción de una fuerza" (https://dle.rae.es/inercia).

${ }^{16}$ Steve Portigal es un reconocido y experimentado UX Researcher (investigador UX) que trabaja actualmente como consultor, conferencista y escritor, para ayudar a las organizaciones a construir prácticas de investigación sólidas. Puede conocerse más sobre Steve Portigal y su trabajo en su sitio web oficial: https://portigal.com/.
} 
- Cuando se cambie de una pregunta -o tema- a otra debe explicitarse el cambio de rumbo con frases transicionales, como por ejemplo: "bien, ahora quiero centrarme en..." o "volvamos a algo que me dijiste antes sobre..."17 (Portigal, 2013, p. 103).

- Respetar los silencios, no temerles aunque puedan resultar incómodos. Muchas veces las personas necesitan pensar una respuesta. Si se "llenan" esos silencios con, por ejemplo, otras preguntas, esto puede llevar a distorsiones en lo que las personas inicialmente iban a contestar. Portigal (2013, p. 84) ejemplifica esto con la pregunta: “¿qué desayunaste ayer?". Supongamos que la persona hace un silencio. Si quien entrevista, ante la incomodidad del silencio, repregunta con sugerencias de respuesta: “¿un tostado? ¿Jugo? ¿O...?”, probablemente, la persona entrevistada, que también puede sentirse incómoda, tome una de esas opciones al suponer que son las respuestas esperadas. Quizá la persona, simplemente, no había desayunado. Por eso, siempre se debe hacer silencio luego de preguntar.

- Siempre que una persona contesta una pregunta, se debe prestar atención a cómo responde, para comprobar si ha interpretado la pregunta en el sentido esperado, 0 no. A veces las personas pueden contestar en un sentido que no era el que se había imaginado al momento de pensar la pregunta. En esos casos, se debe redireccionar a la pregunta, repreguntar, o retomar el tema más adelante.

- Pensar la entrevista como un árbol: de una pregunta, a la que la persona entrevistada responde, quien entrevista puede imaginar dos nuevas preguntas. Frente a una pausa quizá solamente diga: "bien...", dando lugar a que la persona siga hablando y, de eso nuevo que se ha dicho, surjan otras dos posibles preguntas. Portigal señala que, además de "mirar el reloj, mantener contacto visual, tomar notas, y mucho más durante la entrevista", también se debe "gestionar este árbol" (Portigal, 2013, p. 95). Para esto da algunos consejos:

- Esperar a que se den las respuestas a estas preguntas de forma orgánica durante la entrevista.

- Anotarlas para volver a ellas más tarde.

\footnotetext{
${ }^{17}$ En este caso y los siguientes, se procuró reproducir en español las expresiones presentadas por Portigal (2013) en las
} páginas referenciadas. 
- Priorizarlas de acuerdo a los objetivos de la entrevista.

- Respetar -y adoptar - la forma en la que las personas entrevistadas se refieren a las cosas. No importa si una persona no pronuncia correctamente un término o el nombre de alguna marca, o si usa una palabra en un sentido que no resulte familiar o sea incorrecto. Jamás se debe corregir a las personas: el fin de la entrevista es aprender, no enseñar.

- Asumir que lo que nos cuenta una persona tiene sentido y es cierto, aunque se vean inconsistencias en el relato (y/o con lo observado, si la entrevista tiene lugar en un lugar habitual para la persona entrevistada).

- No asumir que las personas entrevistadas adoptan el punto de vista de quien las entrevista. Aunque digan que sí frente a ciertas afirmaciones, eso no quiere decir que verdaderamente están de acuerdo y que adoptan la interpretación de una cosa o situación que hace alguien más. 


\subsection{Fundamentos teóricos para la propuesta de intervención}

A continuación se presentan los fundamentos teóricos de la perspectiva con la que se realizará la propuesta de intervención.

\subsubsection{Estrategia y posicionamiento}

A pesar de que los conceptos de estrategia proliferan, en este trabajo se considerará la definición de Rondas \& Guerra (2012), que se propuso como resultado de un exhaustivo relevamiento de las definiciones más tradicionales del término, enunciadas entre 1962 y 2008. Rondas \& Guerra afirman que "la esencia del concepto de estrategia es la dinámica de la relación entre una empresa y su contexto, en la que se toman las acciones necesarias para cumplir sus objetivos y/o mejorar sus rendimientos, con un uso racional de sus recursos" (2012, p. 182; traducción propia). Esta acepción de la palabra pone el foco en qué tanto se tienen en cuenta los factores externos. Es decir que, aunque a menudo se considera a la estrategia como el conjunto de las acciones que se toman para llegar a un espacio deseado dentro de un mercado, esas acciones no deben desconocer el contexto en el que se encuentra la organización que piensa e implementa una estrategia.

En cuanto al posicionamiento, Kotler (2001) afirma que "consiste en diseñar la oferta de la empresa de modo que ocupe un lugar claro y apreciado en la mente de los consumidores meta" (p. 39). El posicionamiento de una empresa en la mente de las personas es lo que logra que esa empresa pueda ocupar el mencionado espacio deseado dentro de un mercado, o aspirar a ocuparlo.

Finalmente, cuando estos dos conceptos se cruzan nos encontramos con el posicionamiento estratégico que, según Porter (2008b), “implica realizar actividades diferentes de aquellas de los rivales, o bien realizar actividades similares de manera diferente" (p. 4). En este punto, se vislumbra la necesidad de la diferenciación y de pensar propuestas de valor que destaquen a la empresa de sus competidores, mejorando su competitividad y acercándola al lugar que quiere ocupar en un mercado (o ayudándola a mantenerse en él). 


\subsubsection{Planificación}

Para la elaboración de este trabajo, se entiende a la planificación como "una actividad genérica que tiende a la asignación y distribución de recursos, en procura de alcanzar un objetivo". Además, se considera que la planificación "es una actividad de análisis que tiende a ir de lo general a lo particular" y que es un "proceso fundamentalmente analítico" (Terrazas Pastor, 2011, p. 9).

En cuanto a los tipos de planes, se adopta la clasificación propuesta por Robbins \& Coulter (2014), que los diferencian de la siguiente forma:

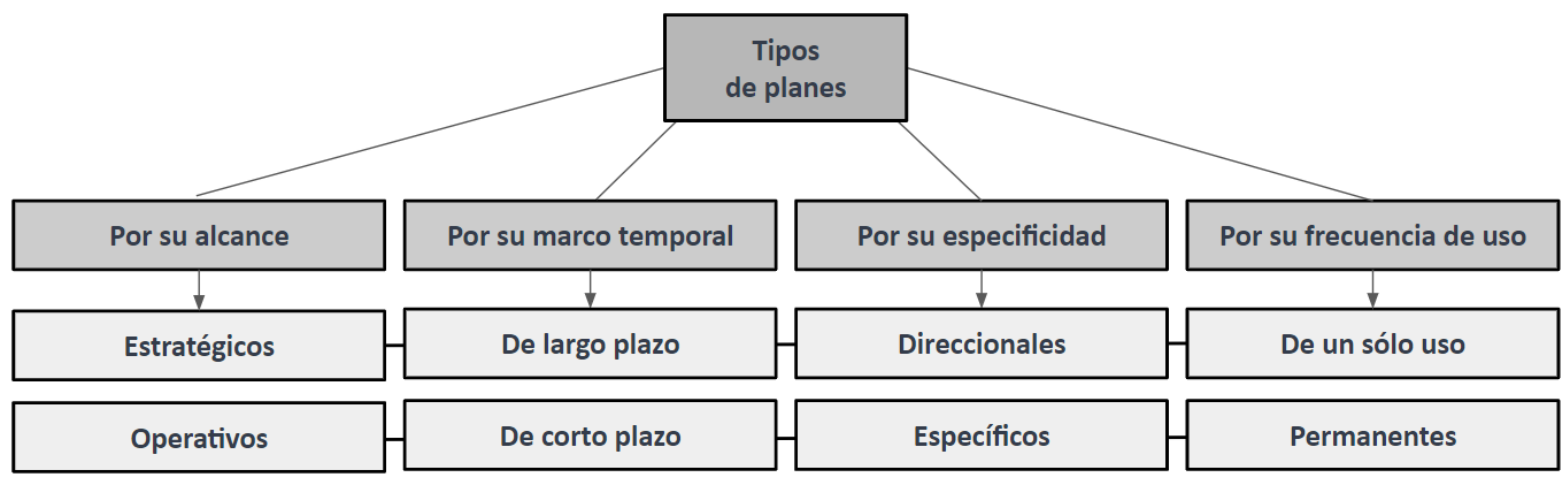

Fuente: Robbins \& Coulter (2014, p. 223).

\subsubsection{Proceso decisorio}

Para la selección de una alternativa de desarrollo, se seguirán los pasos que Robbins \& Coulter (2014, pp. 163-165) proponen como los pasos racionales del proceso decisorio:

1. Identificación de un problema o de una brecha entre la situación actual y la esperada.

2. Identificación de los criterios de decisión relevantes para el problema.

3. Ponderación de los criterios, ya que no todos tienen el mismo nivel de relevancia y es imprescindible asignar un valor que refleje el peso relativo de cada criterio.

4. Desarrollo de las alternativas posibles para solucionar el problema.

5. Análisis de las alternativas, evaluándolas respecto de los criterios ponderados.

6. Selección de una alternativa considerada como la más ventajosa a la hora de solucionar el problema, de acuerdo a su evaluación respecto de los criterios ponderados.

7. Implementación de la alternativa, es decir, su puesta en marcha. 
8. Evaluación de la eficacia de la decisión, es decir, la evaluación del resultado obtenido: ¿el problema se solucionó? Si esto no ocurrió, se deben revisar los pasos del proceso para identificar dónde pudo haber habido un error.

\subsubsection{Gantt}

Para proponer un plan de acción que permita lograr el desarrollo de una versión de la plataforma para dispositivos móviles, es necesario llevar adelante la programación y organización cronológica de las tareas necesarias.

Como menciona Terrazas Pastor (2011), la etapa de planificación previa a un proyecto planea y establece las actividades que lo conforman, y que permiten el cumplimiento final de sus objetivos. Además, señala que:

[L]a única manera de poder ordenar, sistematizar, estructurar la posible realización y ejecución de un programa o proyecto, es a través de la utilización de herramientas y elementos planificadores que a través de reglas sencillas y claras, permitan determinar los supuestos base para aminorar el riesgo de fracaso de la posterior ejecución efectiva de tareas (p. 8).

En este trabajo, se hará uso del reconocido diagrama de Gantt, que tiene su nombre por Henry Gantt, un ingeniero mecánico estadounidense que desarrolló esta herramienta a inicios del siglo XX. Un diagrama de Gantt es una herramienta gráfica que permite establecer y visualizar "la secuencia de ejecución de operaciones" de un proyecto, y que puede usarse "apropiadamente en la planificación de la ejecución de actividades previas para el desarrollo de proyectos" (Terrazas Pastor, 2011, pp. 10-11).

Este diagrama tiene en el eje $X$ (abscisas) el tiempo y en el eje $Y$ (ordenadas) las actividades. Para confeccionarlo, primero se enlistan todas las actividades necesarias para llevar a cabo el proyecto, luego se las ordena según cómo deben sucederse en el tiempo, y a la vez se debe ir estableciendo el tiempo esperado para su consecución.

\subsubsection{Kanban}

Una vez establecidas las actividades, ordenadas cronológicamente y con la estimación de sus plazos, se debe pasar de la programación de tareas a su implementación. En esta "bajada" del plan ideal a la operación real, es imprescindible no perder la organización. Caso contrario, la programación de actividades habrá sido en vano. Sin embargo, suele suceder que en la realidad pueden surgir imprevistos o revelarse situaciones 
que no habían estado (correctamente o en absoluto) contempladas en la planificación y/o programación inicial. Por estos motivos, es que tan crecientemente en los últimos años, se han adoptado las metodologías ágiles, tanto para el planteo de problemas, como para la ideación, desarrollo e implementación de posibles soluciones.

Estamos inmersos en un mundo $\mathrm{BANI}^{18}$ (ya no en un mundo $\mathrm{VUCA}^{19}$ ), y la necesidad de la iteración, validación e implementación (o el error, corrección y nueva validación) ha de ser rápida, flexible, orientada y, sobre todo, constante.

En los últimos años, el método Kanban, se ha adoptado ampliamente en el campo del software. El Kanban es considerado un método ágil (o Agile Method) y herramienta Lean $^{20}$, que tiene numerosos beneficios para proyectos de software. Según Ahmad, Markkula \& Oivo (2013), permite:

- Que las personas del equipo visualicen todo el flujo de trabajo (workflow).

- Establecer y visualizar prioridades y cuellos de botella.

- Que se conozca en qué estado está cada actividad.

- En base a ese conocimiento limitar (y busca, además, minimizar) el trabajo que está en progreso (o WIP, por las iniciales de work in progress).

- Medir el tiempo que toma realizar cada actividad, desde su salida del punto de inicio (Backlog) hasta su finalización (Done), lo que hace que el equipo pueda aprender de (y corregir, de ser necesario) su propio ritmo y ciclos de trabajo.

Aunque en este trabajo no se presentará una propuesta de Kanban, sí se recomendará su uso para la etapa de implementación. Existen distintas formas de conformar las columnas que determinan las etapas de un proceso de principio a fin. La más

\footnotetext{
${ }^{18}$ Acrónimo usado, a partir del 2020 y a causa de los sistemáticos cambios globales y climáticos, para describir un nuevo contexto, caracterizado por ser frágil (brittle), ansioso (anxious), no linear (non-linear) e incomprensible (incomprehensible) (Stefanini, 2021).

${ }_{19}$ Acrónimo usado, desde el fin de la Guerra Fría, para describir un contexto marcado por la volatilidad (volatile) incertidumbre (uncertain), complejidad (complex) y ambigüedad (ambiguous) (Stefanini, 2021).

${ }^{20}$ Las herramientas Lean permiten volver los procesos más eficientes, centrándose en la mejora continua y en la detección y corrección de desvíos que atentan contra la eficiencia. El surgimiento de las primeras de estas herramientas se remonta a los años '50, específicamente en la industria automotriz y en la empresa Toyota, para lo que se conoce como una producción Just-in-time (Ahmad, Markkula \& Oivo, 2013), que busca reducir el stock de inventarios y volver más exacto el tiempo de distribución de los productos.
} 
ampliamente usada es la que se muestra a continuación (sobre la columna central es que se establece el límite de WIP que se mencionó anteriormente):

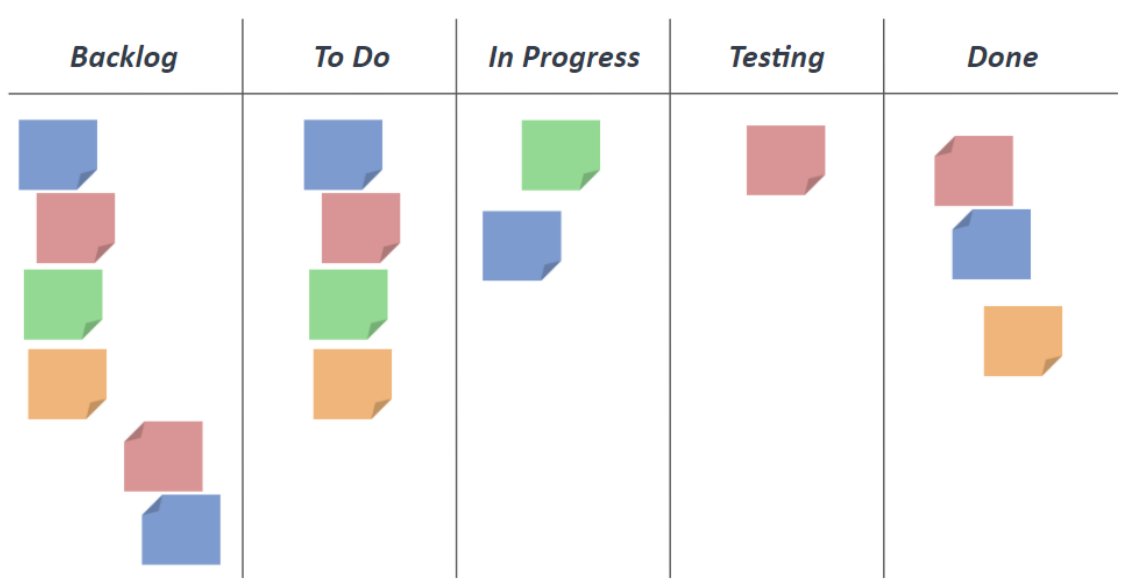

Fuente: http://avanzaproyectos.com/webinars-2/agile-pm-kanban-board/. 


\section{Diagnóstico}

\subsection{Diagnóstico organizacional}

\subsubsection{Breve reseña del surgimiento}

La idea que dio origen a esta empresa surgió en un viaje que hicieron Timothy Zenderman (licenciado en Economía y Contabilidad de Claremont McKenna College, California, Estados Unidos) y su primo Ezequiel Moljo (emprendedor con experiencia en hostels ${ }^{21}$ de Rosario, Santa Fe, Argentina) por Argentina, como mochileros.

En base a vivencias durante ese viaje y a la experiencia en hostels de Moljo, sumado a conversaciones con personas que trabajaban en este tipo de alojamientos, vieron la potencialidad de una plataforma que pudiera identificar a personas que, cuando viajaban, efectuaban robos, evadían pagos, etc. Así nació, en el año 2011, Safe Hostel LLC ${ }^{22}$ : una empresa que ofrecía un software para que quienes tenían o administraban hostels, pudieran tener una base de datos actualizada y compartida entre distintos alojamientos, en la que pudieran saber qué huéspedes traían problemas.

Aunque Safe Hostel no tuvo un gran crecimiento, Zenderman y Moljo pensaron en pivotear y, en lugar de disolver el proyecto, dieron inicio a BananaDesk en el año 2013. Hasta la actualidad, Safe Hostel LLC (DBA ${ }^{23}$ BananaDesk) ofrece su PMS (también llamado BananaDesk) a alojamientos independientes de todas partes del mundo ${ }^{24}$. Un PMS (Property Management System) es un sistema que permite gestionar diferentes aspectos del día a día de un alojamiento.

\footnotetext{
${ }^{21}$ Fue encargado en La Casona, dueño como parte de una sociedad de Rosario Inn y dueño particular de Punto Clave.

${ }^{22}$ LLC o Limited Liability Company es el tipo societario estadounidense, cuyo equivalente en nuestro país es una SRL o Sociedad de Responsabilidad Limitada.

${ }^{23}$ DBA o Doing Business As significa que el nombre de la empresa es ficticio, y se le permite operar bajo esa denominación, aunque no sea aquella con la que la empresa se encuentra registrada.

${ }^{24}$ En el anexo se muestran datos respecto de la geolocalización de clientes.
} 


\subsubsection{Business Model Canvas}

A continuación, se muestra el modelo de negocio de BananaDesk en un Business

Model Canvas. Luego se describirán sus componentes con mayor detalle.

\begin{tabular}{|c|c|c|c|c|}
\hline \multirow[t]{2}{*}{$\begin{array}{l}\text { Asociaciones } \\
\text { clave } \\
\text { - Channex } \\
\text { - MyAllocator } \\
\text { - Booking.com } \\
\text { - Hostelworld } \\
\text { - Clientes }\end{array}$} & $\begin{array}{l}\text { Actividades clave } \\
\text { Dar soporte } \\
\text { personalizado a } \\
\text { clientes } \\
\text { - Monitorear el } \\
\text { correcto } \\
\text { funcionamiento } \\
\text { de los } \\
\text { servidores } \\
\text { Monitorear la } \\
\text { correcta } \\
\text { actualización de } \\
\text { las } \\
\text { disponibilidad y } \\
\text { las tarifas de los } \\
\text { alojamientos } \\
\text { Desarrollar y } \\
\text { actualizar } \\
\text { funcionalidades } \\
\text { de la plataforma }\end{array}$ & \multirow[t]{2}{*}{$\begin{array}{l}\text { Propuestas de } \\
\text { valor } \\
\text { - } \\
\text { Se ofrece } \\
\text { asesoramiento y } \\
\text { trato } \\
\text { personalizado } \\
\text { desde la } \\
\text { creación de la } \\
\text { cuenta } \\
\text { Es una } \\
\text { plataforma } \\
\text { intuitiva y fácil } \\
\text { de aprender y } \\
\text { enseñar a usar } \\
\text { Se organizan las } \\
\text { reservas y los } \\
\text { procesos de } \\
\text { recepción y se } \\
\text { previenen } \\
\text { sobreventas }\end{array}$} & $\begin{array}{l}\text { Relaciones con } \\
\text { clientes } \\
\text { - Asistencia } \\
\text { personal } \\
\text { exclusiva }\end{array}$ & \multirow[t]{2}{*}{$\begin{array}{l}\text { Segmentos de } \\
\text { mercado } \\
\text { - Hostels } \\
\text { - Hosterías } \\
\text { - Bed \& Breakfast } \\
\text { - Cabañas } \\
\text { - Campings } \\
\text { - Departamentos } \\
\text { - Hoteles } \\
\text { - } \text { boutique } \\
\text { Hoteles } \\
\text { pequeños }\end{array}$} \\
\hline & $\begin{array}{ll}\text { Recursos clave } \\
\text { - } & \text { Recursos } \\
& \text { humanos } \\
\text { - } & \text { Recursos } \\
& \text { financieros } \\
\text { - } & \text { Servidores }\end{array}$ & & $\begin{array}{ll}\text { Canales } \\
\text { - } \\
\text { - } & \text { Publicidades } \\
\text { - } & \text { Email } \\
\text { - } & \text { Boca en boca } \\
\text { - WhatsApp } \\
\text { - Llamadas } \\
& \text { telefónicas }\end{array}$ & \\
\hline \multicolumn{2}{|c|}{$\begin{array}{l}\text { Estructura de costos } \\
\text { - Pago de servidores } \\
\text { - Pago de plataformas } \\
\text { - } \quad \text { Pago de sueldos } \\
\text { - Pago de publicidades }\end{array}$} & \multicolumn{3}{|c|}{$\begin{array}{l}\text { Fuentes de ingresos } \\
\text { - Pago por el uso de la plataforma }\end{array}$} \\
\hline
\end{tabular}

Fuente: Becka, Cimatti, Giraldo y González Botasi (2021); elaboración propia.

- Segmentos de mercado: BananaDesk cuenta con 180 clientes en distintas partes del mundo. Casi el $70 \%$ de estos alojamientos se encuentra en América Latina y, de éstos, un $27 \%$ son argentinos (ver Anexo, puntos 1.1. y 1.2.). Aunque en un inicio 
estaba únicamente dirigido a hostels, la pandemia de COVID-19, ocasionó que el target se ampliara a otro tipo de alojamientos independientes: hostels, hosterías, bed \& breakfast, cabañas, campings, departamentos, hoteles boutique o pequeños.

- Propuestas de valor: existen dos tipos de propuestas de valor para quienes contratan la plataforma. Por un lado, hay dos propuestas de valor que diferencian a BananaDesk de sus competidores:

- El asesoramiento y trato personalizado que se da desde el primer momento: se explica el funcionamiento de la plataforma, se ayuda a configurar la cuenta (especialmente las habitaciones y tarifas) y a conectar las OTAs ${ }^{25}$, etc.

- Lo intuitiva que es la plataforma y, por eso, lo fácil que resulta aprender y enseñar a usarla (muchas otras plataformas, quizá por tener múltiples funcionalidades, que generalmente los alojamientos pequeños no necesitan, se tornan muy complejas de usar y esto suele alargar la curva de aprendizaje de los recepcionistas ${ }^{26}$, además de que pueden derivar en mayores errores humanos).

Por otro lado, están las propuestas de valor que tienen que ver con las soluciones que ofrecen este tipo de plataformas para quienes las usen:

- Una correcta gestión de las reservas.

- Un mayor orden en la recepción del alojamiento.

- La actualización automática de la disponibilidad y tarifas de los alojamientos en sus canales de venta (lo que previene la sobreventas u overbookings) ${ }^{27}$. Finalmente, otras de las soluciones que ofrece la plataforma son:

\footnotetext{
${ }^{25}$ OTAs, Online Travel Agencies, o Agencias de Viaje Online, son aquellos sitios donde se comercializan pasajes, reservas, excursiones y paquetes turísticos, como Booking.com, Hostelworld, Despegar, Airbnb, Expedia, Agoda, etc.

${ }^{26}$ Algunos modelos de negocio en alojamientos pequeños tienen como característica una alta rotación del personal de recepción. Por ejemplo, en los hostels a menudo esta rotación está causada por la presencia de personas que viajan como voluntarias para trabajar en recepciones de alojamientos, a cambio de una cama en el mismo. Puede leerse más de este tema en: https://bananadesk.com/blog/voluntarios-vs-recepcionistas.

${ }^{27} \mathrm{Si}$ la disponibilidad de un alojamiento no está actualizada en todos los lugares desde los que se pueden hacer reservas (sean OTAs o canales de reserva directa), puede ocurrir que se reserve al mismo tiempo una misma habitación o cama en una misma fecha, a través más de un canal. Esto es costoso para el alojamiento, no solo en términos financieros (porque puede perder la reserva que esté duplicada si tiene que cancelarla en lugar de modificarla) sino de imagen (porque puede, además, inhibir posibles reservas futuras si, por ejemplo, la persona que tuvo que cancelar la reserva deja un mal comentario en redes sociales).
} 
- Se pueden crear habitaciones compartidas y vender camas, así como habitaciones privadas que se venden como una única unidad ${ }^{28}$.

- Se pueden fijar tarifas base y por temporada, y variar los precios por canal.

- Se pueden vender extras o servicios adicionales.

- Se pueden ver las transacciones realizadas en el alojamiento y exportar reportes en Excel.

- Se pueden ver métricas en un dashboard, y generar y exportar reportes en Excel.

- Es posible integrar un motor de reservas (desarrollado por la empresa ${ }^{29}$ ) para recibir reservas directas, evitando las comisiones de las OTAs.

- Se pueden crear Users ilimitados con distintos permisos de acceso y edición.

- Canales: los canales a través de los que BananaDesk llega a clientes potenciales son: su $w_{e} b^{30}$, publicidades (se han hecho campañas publicitarias en Facebook Ads, Google Ads y Microsoft Ads), campañas de email marketing (y envío de Newsletter usando plataformas como Mixmax y Convertkit) y, principalmente, el boca en boca. Muchos alojamientos que comienzan a interactuar con BananaDesk, han sido recomendados $^{31}$ por otros alojamientos. Una vez que los alojamientos ya son clientes, la interacción se realiza casi exclusivamente por el chat de soporte de la plataforma (Intercom es la plataforma que se usa), WhatsApp o llamadas telefónicas.

- Relaciones con clientes: las relaciones que BananaDesk establece con sus clientes es de una asistencia personal exclusiva, con un acompañamiento en todo el proceso de onboarding, asesoramiento (sobre todo respecto de cuestiones técnicas para que las configuraciones dentro del PMS y de las OTAs estén correctamente hechas) y un trato personalizado durante todo el tiempo que se use la plataforma.

- Fuentes de ingreso: la plataforma ofrece un período de 14 días de prueba gratuita y, si se decide contratar el servicio, tiene un sistema de precios que se basa en distintas tarifas, dependiendo de la capacidad máxima de los alojamientos. Los planes solo

\footnotetext{
${ }^{28}$ Las ventas siempre son por unidades, pero éstas pueden ser habitaciones enteras o camas, dependiendo de que las habitaciones sean privadas o compartidas.

${ }^{29}$ Es decir, que no es un servicio que se integre desde otra plataforma mediante una API.

${ }^{30}$ Puede visitarse en: https://bananadesk.com/es/.

${ }^{31}$ Por cada cliente nuevo que viene recomendado por un cliente actual, BananaDesk le bonifica un mes a cada alojamiento.
} 
varían por la capacidad de los alojamientos, es decir, que el precio no depende de las funcionalidades incluidas, sino que con todos ellos se puede usar la plataforma en su totalidad. Cabe destacar que, como la plataforma solo puede usarse si se la contrata y se paga por ella, todas las personas usuarias de la plataforma pertenecen a alojamientos que son clientes.

Los planes vigentes son:

- Extra Small (10 huéspedes o menos - 29 USD)

- Small (11 a 35 huéspedes - 49 USD)

- Medium (36 a 55 huéspedes - 69 USD)

- Large (56 a 80 huéspedes - 99 USD)

- Extra Large (80 huéspedes o más - 129 USD) $)^{32}$

Estas tarifas pueden pagarse mensualmente o en plan anual (que equivale a diez meses), con tarjeta de crédito o a través de PayPal.

Como resultado de la pandemia de COVID-19, se perdieron una gran cantidad de alojamientos clientes, haciendo que la facturación caiga. Aunque el turismo (entendido no solo como una actividad económica, sino también social y cultural) se encuentra en una fase de recuperación, aún no se han restablecido los niveles de facturación de los primeros meses del 2020 (cuando la plataforma registraba la mayor cantidad de clientes desde sus inicios).

- Recursos clave: entre los recursos clave, además de los financieros, se destacan los recursos humanos. BananaDesk está compuesta, además de por Timothy Zenderman (CEO \& Co-Founder) y Ezequiel Moljo (Co-Founder \& Manager), por personas que se dedican a hacer soporte, onboarding, facturación, investigación y creación de contenidos. Por otra parte, se articula horizontalmente con otras personas que trabajan en las áreas de: diseño, desarrollo y programación, y marketing. Aunque la

\footnotetext{
32 Por los impuestos que se aplican en Argentina sobre los pagos hechos en USD, desde diciembre del 2020, la empresa tiene un tarifario especial en ARS que se cobra a través de Mercado Pago. Es el único país para el que tiene una opción de pago en moneda local.
} 
estructura organizacional podría pensarse como de línea y staff ${ }^{3}$, la realidad es decisiones suelen consultarse y consensuarse con todo el equipo ${ }^{34}$.

- Actividades clave: entre las múltiples actividades que se llevan a cabo en BananaDesk, algunas son imprescindibles para que se puedan cumplir las propuestas de valor. Ejemplos de estas actividades son: el dar soporte personalizado a clientes, monitorear el correcto funcionamiento de los servidores y de la actualización automática de la disponibilidad y tarifas, y desarrollar y actualizar funcionalidades de la plataforma.

- Asociaciones clave: entre las asociaciones clave se destaca la relación con las empresas proveedoras de conexiones con OTAs. Las empresas que proveen a los PMS estas integraciones, para que los alojamientos que los usan puedan vender en las OTAs, se llaman Channel Managers (CMs). Sin embargo, un PMS también puede tener una integración directa con las OTAs (siendo un partner de éstas).

BananaDesk se integra directamente (es decir, sin un CM como proveedor intermediario) con Booking.com y Hostelworld. Además, actualmente BananaDesk se integra con dos $\mathrm{CMs}$, ya que está migrando de uno a otro. El que se usaba hasta el momento era MyAllocator, que pertenece a Cloudbeds (empresa competidora y líder del mercado). Sin embargo, se ha trabajado en la integración con Channex, otro CM, para poder dejar de usar la integración anterior. Esto es así, por un lado, porque se quiere dejar de tener a una empresa competidora como proveedora y, por otro lado, porque esa integración es más costosa para quienes usan la plataforma (que si quieren integrarse a los canales que ofrece MyAllocator, deben pagarle ese servicio) que la que ofrece Channex. Cuando la integración esté finalizada, se migrarán las conexiones de todos los alojamientos y se dejará de usar a MyAllocator como proveedor de las conexiones con las OTAs.

\footnotetext{
${ }^{33}$ Este tipo de estructura organizacional resulta "de la combinación de la organización lineal y la funcional para tratar de aumentar las ventajas de estos dos tipos de organización y reducir sus desventajas para formar la llamada organización jerárquica-consultiva" (Minsal Pérez \& Pérez Rodríguez, 2007, p. 6).

${ }^{34}$ No se profundizará en este trabajo en cuestiones estrictamente organizacionales. Sin embargo, solo para mencionar algún aspecto referido a la cultura organizacional de la empresa, esta puede calificarse como una cultura anticipadora (de acuerdo con la clasificación de Ansoff, disponible en Díaz \& Ortiz, 2001). Asimismo, está marcada por la unión del equipo de trabajo, la comunicación frecuente y fluida, y el consenso de todas las partes en la toma de decisiones.
} 
- Estructura de costos: como ocurre con muchas empresas de software pequeñas, la estructura de costos no involucra el pago de alquileres de oficina, gastos de administración ni pago de servicios como luz y gas. La empresa no cuenta con activos fijos de ningún tipo. Su estructura de costos está compuesta por el pago de las plataformas que usa para su funcionamiento (como las mencionadas Intercom o Convertkit, y otras como Mailchimp o Mixpanel), el pago de sueldos (fijados en cantidad de horas de trabajo de cada persona), el pago de publicidades y el pago por el uso de servidores (se contratan servidores de $A m a z o{ }^{35}$ ).

\subsubsection{Matriz FODA}

A continuación, se muestran los factores actuales internos y externos a BananaDesk, en una matriz FODA:

\begin{tabular}{|c|c|}
\hline Fortalezas & Debilidades \\
\hline $\begin{array}{l}\text { - En términos de soporte, no hay } \\
\text { respuestas de bots, } \\
\text { siempre contestan personas. } \\
\text { - } \quad \text { El trato es personalizado y las personas lo } \\
\text { reciben positivamente. } \\
\text { - Hay, dentro de la empresa, personas con } \\
\text { conocimientos en turismo y experiencias en } \\
\text { alojamientos. } \\
\text { No suele haber fallas en el sistema de gestión } \\
\text { de reservas, por lo que muy esporádicamente } \\
\text { hay sobreventas. } \\
\text { Se ofrecen conexiones con los canales de venta } \\
\text { más relevantes para los alojamientos que } \\
\text { forman parte del target. }\end{array}$ & $\begin{array}{l}\text { - No hay una gran cantidad de clientes, por lo } \\
\text { que la facturación no es muy alta. Esto impide } \\
\text { el crecimiento, tanto en términos de personal } \\
\text { como de desarrollos, sean de mejora o de } \\
\text { creación de funcionalidades. } \\
\text { - No existen grandes acciones de marketing que } \\
\text { apunten a la conversión de nuevos clientes. } \\
\text { No existe una versión de la plataforma en } \\
\text { dispositivos móviles. }\end{array}$ \\
\hline Oportunidades & Amenazas \\
\hline $\begin{array}{l}\text { - Existe una tendencia mundial hacia la } \\
\text { digitalización. } \\
\text { - } \quad \text { Los alojamientos necesitan contar con más } \\
\text { herramientas tecnológicas para ser } \\
\text { competitivos en el mercado. } \\
\text { - Los turistas post COVID-19 seguramente } \\
\text { buscarán alojamientos como los que son el } \\
\text { target de BananaDesk, por tener capacidades }\end{array}$ & $\begin{array}{l}\text { - La tendencia al uso de dispositivos móviles } \\
\text { exige tener esta versión, que muchos } \\
\text { competidores ya tienen. } \\
\text { - Aún hay incertidumbre respecto a cuánto } \\
\text { tardará en recuperarse por completo la } \\
\text { actividad turística, luego de la pandemia de } \\
\text { COVID-19. }\end{array}$ \\
\hline
\end{tabular}

\footnotetext{
${ }^{35}$ Se usan ocho servidores EC2 para el funcionamiento general de la plataforma, dos load balancers, que regulan la carga entre la red y las instancias EC2, doce buckets S3, que sirven a modo de "repositorio" (de imágenes y estilos, por ejemplo), y una base de datos RDS, donde se almacenan los datos de clientes.
} 
más reducidas que los grandes hoteles de cadenas.
- Hay competidores en el mercado que tienen mayores recursos y pueden hacer más desarrollos rápidamente, a medida que la tecnología avanza y las conductas se modifican.

- Las personas están más informadas y conscientes de los beneficios de otras herramientas.

Fuente: Becka, Cimatti, Giraldo y González Botasi (2021); elaboración propia.

A continuación, se confecciona la matriz de Evaluación de los Factores Internos (MEFI):

\begin{tabular}{|c|c|c|c|}
\hline Factor a analizar & Peso & Calificación & Peso ponderado \\
\hline \multicolumn{4}{|c|}{ Fortalezas } \\
\hline No hay soporte hecho por bots & 0,08 & 2 & 0,16 \\
\hline El trato es personalizado & 0,20 & 4 & 0,8 \\
\hline Hay personal con experiencia en el rubro & 0,06 & 1 & 0,06 \\
\hline $\begin{array}{l}\text { No suele haber fallas en el sistema de gestión de } \\
\text { reservas }\end{array}$ & 0,12 & 4 & 0,48 \\
\hline $\begin{array}{l}\text { Se ofrecen conexiones con los canales de venta } \\
\text { más relevantes para el target }\end{array}$ & 0,08 & 2 & 0,16 \\
\hline Total de las Fortalezas & 0,54 & - & 1,66 \\
\hline \multicolumn{4}{|c|}{ Debilidades } \\
\hline No hay una gran cantidad de clientes & 0,22 & 4 & 0,88 \\
\hline $\begin{array}{l}\text { No existen grandes acciones marketing para } \\
\text { convertir nuevos clientes }\end{array}$ & 0,16 & 3 & 0,48 \\
\hline $\begin{array}{l}\text { No existe una versión de la plataforma en } \\
\text { dispositivos móviles }\end{array}$ & 0,08 & 2 & 0,16 \\
\hline Total de las Debilidades & 0,46 & - & 1,52 \\
\hline Total & 1,00 & - & 3,18 \\
\hline
\end{tabular}

A modo interpretativo, con la representación de los pesos ponderados de los factores internos que permite ver la MEFI, puede verse que el total de las fortalezas es mayor que el de las debilidades, pero no lo es por mucho $(1,66$ contra 1,52$)$. Por tener las fortalezas un peso mayor, se puede decir que los factores internos son favorables para la empresa. Sin embargo, se debe tener en cuenta que el límite es muy fino, por lo que se debe tener 
especial cuidado y atender a las debilidades, para evitar que el medio ambiente interno se vuelva desfavorable.

Por último, se confecciona la matriz de Evaluación de los Factores Externos (MEFE):

\begin{tabular}{|l|c|c|c|}
\hline \multicolumn{1}{|c|}{ Factor a analizar } & Peso & Calificación & Peso ponderado \\
\hline \multicolumn{2}{|c|}{ Oportunidades } \\
\hline $\begin{array}{l}\text { Hay una tendencia mundial hacia la } \\
\text { digitalización }\end{array}$ & 0,16 & 2 & 0,32 \\
\hline $\begin{array}{l}\text { Necesidad de los alojamientos de incorporar } \\
\text { herramientas tecnológicas para ser } \\
\text { competitivos }\end{array}$ & 0,25 & 3 & 0,75 \\
\hline $\begin{array}{l}\text { Los turistas post CoVID-19 seguramente } \\
\text { buscarán alojamientos como los que son el } \\
\text { target }\end{array}$ & 0,06 & 1 & 0,06 \\
\hline \multicolumn{1}{|c|}{ Total de las Oportunidades } & 0,47 & - & 1,13 \\
\hline \multicolumn{2}{|c|}{ Amenazas } & \multicolumn{1}{|l|}{} \\
\hline $\begin{array}{l}\text { La tendencia mundial al uso de dispositivos } \\
\text { móviles exige tener esta versión }\end{array}$ & 0,25 & 1 & 0,25 \\
\hline $\begin{array}{l}\text { Aún hay incertidumbre respecto a cuánto } \\
\text { tardará en recuperarse por completo la } \\
\text { actividad turística }\end{array}$ & 0,07 & 2 & 0,14 \\
\hline $\begin{array}{l}\text { Hay competidores en el mercado que tienen } \\
\text { mayores recursos y pueden hacer más } \\
\text { desarrollos rápidamente }\end{array}$ & 0,16 & 2 & $\mathbf{1 , 9 4}$ \\
\hline $\begin{array}{l}\text { Las personas están más informadas y } \\
\text { conscientes de los beneficios de otras } \\
\text { herramientas }\end{array}$ & 0,05 & $\mathbf{1}$ & 0,81 \\
\hline $\begin{array}{l}\text { Total de las Amenazas } \\
\text { Total }\end{array}$ & $\mathbf{0 , 5 3}$ & - & 0,32 \\
\hline
\end{tabular}

A modo interpretativo, con la representación de los pesos ponderados de los factores externos que permite ver la MEFE, puede verse que el total de 1,94 indica que la empresa está "por debajo de la media en cuanto al esfuerzo por seguir estrategias que permitan aprovechar las oportunidades externas y evitar las amenazas externas" (Talancón, 2007, p. 119). Por otra parte, no se debe perder de vista que el peso ponderado de las oportunidades 
es mayor al peso ponderado de las amenazas $(1,13$ contra 0,81$)$, por lo que los factores externos son favorables para la empresa.

\subsubsection{Matriz de fuerzas competitivas}

A continuación se muestran las fuerzas competitivas según la estructura de Porter. Se las puntuó considerando 1 como el valor más bajo y 5 como el más alto, con el fin de determinar, en base a ciertas variables, la intensidad de estas fuerzas. Luego se las analizó según cómo influyen sobre BananaDesk:

\section{- Amenaza de nuevos entrantes:}

\begin{tabular}{|l|c|}
\hline \multicolumn{1}{|c|}{ Variables - Barreras de entrada } & 5 \\
\hline Existencia de economías de escala & 4 \\
\hline Existencia de efectos de red & 3 \\
\hline Costos de sustitución por parte de clientes & 4 \\
\hline Altos requerimientos de capital inicial & 5 \\
\hline Ventajas de actores establecidos & 4 \\
\hline Dificultad de acceso a canales de distribución & 3 \\
\hline Políticas restrictivas & $\mathbf{2 8}$ \\
\hline \multicolumn{1}{c}{ Total } & Puntuación \\
\hline
\end{tabular}

\begin{tabular}{|c|c|}
\hline Rangos & Puntaje \\
\hline Alto & mayor o igual a 28 puntos \\
\hline Medio & entre 14 y 28 puntos \\
\hline Bajo & menor o igual a 14 puntos \\
\hline
\end{tabular}

Como las barreras de entrada al sector se perciben como altas, la amenaza de nuevos entrantes sería baja y, como consecuencia, también lo sería el riesgo de que la rentabilidad del sector baje. Esto es así, entre otras cosas, por haber beneficios para actores ya establecidos, además de que los costos marginales (por ejemplo, de procesamientos de reservas) decrecen relativamente cuando aumenta la cantidad de clientes. 
- Amenaza de productos o servicios sustitutos:

\begin{tabular}{|l|c|}
\hline \multicolumn{1}{|c|}{ Variables } & Puntuación \\
\hline Más funcionalidades & 4 \\
\hline Mejores funcionalidades & 2 \\
\hline Precios más bajos & 2 \\
\hline Facilidad de acceso & 4 \\
\hline Costos de sustitución por parte de clientes & 3 \\
\hline \multicolumn{1}{|c|}{ Total } & 15 \\
\hline
\end{tabular}

\begin{tabular}{|c|c|}
\hline Rangos & Puntaje \\
\hline Alto & mayor o igual a 20 puntos \\
\hline Medio & entre 10 y 20 puntos \\
\hline Bajo & menor o igual a 10 puntos \\
\hline
\end{tabular}

En este caso, se considera la amenaza de sustitutos de otros productos y/o servicios que pueden cumplir la misma función que BananaDesk. Se contemplan en este punto también las planillas en papel y planillas de Excel o Google Sheets. Aunque no son sustitutos perfectos (principalmente porque no tienen una conexión con los canales de venta, no permiten actualizaciones automáticas de disponibilidad y tarifas ni protegen contra los overbookings), muchos de los alojamientos que usan o han usado BananaDesk en sus recepciones, empleaban este tipo de planillas para cumplir el Job general de administrar sus alojamientos.

Se percibe una amenaza media de productos y/o servicios sustitutos. Muchas de las plataformas ofrecidas por las empresas competidoras tienen más funcionalidades aunque, como se mencionó anteriormente, eso no siempre es útil para alojamientos pequeños. Aunque es sumamente fácil acceder a otras plataformas $u$ otro tipo de sustitutos, existe un costo relativamente alto de sustitución por parte de los alojamientos clientes (que no siempre es económico, sino que representa un esfuerzo de aprendizaje, adaptación, configuración, migración de la información, etc.). 
- Poder de negociación de compradores:

\begin{tabular}{|l|c|}
\hline \multicolumn{1}{|c|}{ Variables } & Puntuación \\
\hline Cantidad de clientes & 5 \\
\hline Tamaño de clientes & 1 \\
\hline Diferenciación del producto o servicio ofrecido & 3 \\
\hline Costos de sustitución por parte de clientes & 3 \\
\hline Relevancia de la calidad & 3 \\
\hline \multicolumn{1}{|c|}{ Total } & 15 \\
\hline
\end{tabular}

\begin{tabular}{|c|c|}
\hline Rangos & Puntaje \\
\hline Alto & mayor o igual a 20 puntos \\
\hline Medio & entre 10 y 20 puntos \\
\hline Bajo & menor o igual a 10 puntos \\
\hline
\end{tabular}

El poder de negociación de quienes contratan el servicio se encuentra en un rango medio. Esto es así, principalmente, porque los alojamientos que son el target de BananaDesk son en general pequeños y numerosos, por lo que no tienen un alto poder de negociación (como los que pueden tener, por ejemplo, las más grandes y reconocidas cadenas hoteleras).

\section{- Poder de negociación de proveedores:}

\begin{tabular}{|l|c|}
\hline \multicolumn{1}{|c|}{ Variables } & Puntuación \\
\hline Concentración del sector & 2 \\
\hline Relevancia del sector & 1 \\
\hline Costos de sustitución por parte de las empresas & 2 \\
\hline Diferenciación del producto o servicio ofrecido & 2 \\
\hline Existencia de proveedores sustitutos & 2 \\
\hline Total & 9 \\
\hline
\end{tabular}




\begin{tabular}{|c|c|}
\hline Rangos & Puntaje \\
\hline Alto & mayor o igual a 20 puntos \\
\hline Medio & entre 10 y 20 puntos \\
\hline Bajo & menor o igual a 10 puntos \\
\hline
\end{tabular}

En este caso, se tiene en cuenta como proveedores no solo a los CMs, sino también a los servidores y las plataformas que utiliza BananaDesk para su funcionamiento, mencionadas anteriormente en este trabajo.

El poder de negociación de las empresas proveedoras se ubica en un rango bajo. Esto ocurre porque los PMS no son un sector concentrado ni relevante para, por ejemplo, Amazon o Intercom. Existen, además, múltiples proveedores sustitutos y los costos de sustitución son bajos, sobre todo en cuanto a las plataformas que utiliza BananaDesk para su funcionamiento.

\section{- Rivalidad entre competidores existentes:}

\begin{tabular}{|l|c|}
\hline \multicolumn{1}{|c|}{ Variables } & Puntuación \\
\hline Cantidad de competidores & 4 \\
\hline Tamaño de competidores & 2 \\
\hline Crecimiento lento de la demanda & 4 \\
\hline Aspiración a liderar el mercado & 2 \\
\hline Barreras de salida & 1 \\
\hline Diferenciación del producto o servicio ofrecido & 2 \\
\hline \multicolumn{1}{|c|}{ Total } & 15 \\
\hline
\end{tabular}

\begin{tabular}{|c|c|}
\hline Rangos & Puntaje \\
\hline Alto & mayor o igual a 24 puntos \\
\hline Medio & entre 12 y 24 puntos \\
\hline Bajo & menor o igual a 12 puntos \\
\hline
\end{tabular}

En este caso, se identifican como competidores existentes a Cloudbeds (que es, además, la empresa líder del mercado), Front Desk Master, Hotel Runner, Loventis, Switch, 
Book.World, New Hotel, Sirvoy, Hostelogix, Hotelier, Wubook, Lobby, Pxsol y Buddy. Aunque se sabe que existen más, se identifican las anteriores por ser las principales desde las que vienen (o hacia las que migran) los alojamientos que son clientes de BananaDesk.

La rivalidad de las empresas competidoras se ubica en un rango medio, pero cercano al rango bajo. Esto ocurre porque, aunque existen numerosas empresas competidoras, lo que aumenta la rivalidad, éstas no suelen ser de gran tamaño. Por otro lado, tampoco hay grandes aspiraciones al liderazgo del mercado ni altas barreras de salida.

El punto más relevante a tener en cuenta respecto de la rivalidad existente entre las empresas del sector es el lento crecimiento (sumado a un previo y abrupto decrecimiento) de la demanda, como consecuencia de la situación crítica que sufrió $-\mathrm{y}$ continúa sufriendo- la actividad turística a nivel mundial, por la pandemia de COVID-19. Esto aumenta la rivalidad del sector. Sin embargo, este aspecto puede revertirse rápidamente, si la situación sanitaria a nivel global se recuperara.

En resumen, las fuerzas competitivas identificadas, hacen que el sector en que se encuentra BananaDesk tenga una intensidad competitiva media-baja. Gráficamente, puede verse esto en la siguiente tabla:

\begin{tabular}{|c|c|}
\hline Fuerzas & Bajo \\
\hline Amenaza de nuevos entrantes & $\mathbf{x}$ \\
\hline Amenaza de productos o servicios sustitutos & $\mathbf{x}$ \\
\hline Poder de negociación de compradores & $\mathbf{x}$ \\
\hline Poder de negociación de proveedores & $\mathbf{x}$ \\
\hline Rivalidad entre competidores existentes & $x$ \\
\hline Competitividad del sector & $\mathbf{x}$ \\
\hline
\end{tabular}

Generalmente, un sector que no tiene una muy alta competitividad, sí tiene un gran atractivo para los actores que ya forman parte de él, porque es razonable tener expectativas de poder aumentar la rentabilidad. En este mismo sentido, se espera una recuperación de la actividad turística, que podría hacer crecer los niveles de demanda, ante unas mismas barreras de entrada altas. Aunque una mayor demanda podría aumentar inicialmente la 
rivalidad entre los actores existentes, la expectativa por poder captar una buena porción de esos alojamientos, puede ser una buena razón para buscar estrategias de consolidación dentro del sector. 


\subsection{Identificación de las necesidades de las personas usuarias}

Entre los meses de agosto y octubre de 2020, en BananaDesk se hicieron entrevistas semiestructuradas con el fin de conocer el uso que dan las personas usuarias a la plataforma desde dispositivos móviles ${ }^{36}$ y sus necesidades en torno a un eventual desarrollo.

Lo que motivó esa investigación cualitativa, además del reconocimiento de la necesidad de ofrecer una versión mobile de la plataforma, fue el análisis de métricas que mostraban que, tanto en Europa como en América Latina (que son los continentes donde se encuentran la mayor cantidad de clientes, ver Anexo 1.1.), había crecido la proporción del uso de BananaDesk en dispositivos móviles ${ }^{37}$ respecto de su uso en la versión desktop, durante las cuarentenas más estrictas.

Aunque se sabía que bajo determinadas circunstancias (por ejemplo, no poder ir al alojamiento a trabajar, para aquellas personas que no viven en ellos ni se encuentran cerca) se había usado más la plataforma en dispositivos móviles que en desktop, las métricas que se observaban en Mixpanel solo mostraban cuantitativamente cuántos usos había hecho cada alojamiento en cada sección de la plataforma y desde qué tipo de dispositivo. Sin embargo, más allá de un listado numérico y gráficas que indicaban las secciones (calendar, transactions, dashboard, reservation details, agenda, etc. ${ }^{38}$ ) que más se habían usado, no se sabía qué se había hecho en cada sección, ni para qué se había usado la plataforma desde ese dispositivo en ese momento.

Entonces, con el objetivo general de conocer qué usos se le daba a la plataforma en dispositivos móviles y, específicamente, entender quiénes (administradores, recepcionistas, etc.), dónde (alojamiento, auto, supermercado, etc.), cuándo (momento del día) y para qué (qué se quería hacer, qué se hacía, qué limitaciones se encontraban, etc.) la usaban, fue que se estructuró la investigación. El entendimiento de estos aspectos, permitió identificar cuáles son las razones que hacen que las personas usuarias realicen las acciones que declaran realizar.

\footnotetext{
${ }^{36}$ Se consideraron tanto smartphones como tablets.

${ }^{37}$ Como se mencionó anteriormente, la plataforma se puede usar desde un dispositivo móvil, pero su visibilidad y uso no están optimizados para este tipo de dispositivos, por lo que no se ajusta a la pantalla y se dificulta su uso, además de que algunas acciones no pueden hacerse.

${ }^{38}$ En el Anexo 2 se muestran capturas de pantalla de algunas de las secciones de la plataforma. Estas imágenes no pertenecen a una cuenta real de ningún alojamiento.
} 
En esa ocasión se contactó a personas usuarias de alojamientos latinoamericanos y europeos que, en los últimos 180 días (desde el 10 de agosto del 2020), hubieran tenido más de 180 usos en dispositivos móviles (excluyendo la sección del calendario, ya que es la que aparece por defecto al abrir la plataforma, cuando se inicia sesión).

Para este tipo de investigaciones con personas usuarias en BananaDesk, se sigue buscando interactuar con más personas que cumplan con la categoría que se haya seleccionado como referencia, hasta que las respuestas que dan empiezan a ser las mismas. Cuando una persona que usa la plataforma en Kosovo, responde a una pregunta en el mismo sentido que lo hace otra persona que la usa en Costa Rica o en Chile (por ejemplo), se considera que la "pauta" del uso va en ese sentido.

Se entrevistó, de acuerdo con el enfoque y las buenas prácticas presentadas en el apartado 4.3., a personas que trabajaban en nueve alojamientos de distintos países de América Latina, según el siguiente detalle:

\begin{tabular}{|c|c|c|}
\hline Alojamiento & País & Sección más usada \\
\hline 1 & Costa Rica & Dashboard \\
\hline 2 & Panamá & Dashboard \\
\hline 3 & Costa Rica & Detalles de reserva \\
\hline 4 & Argentina & Detalles de reserva \\
\hline 5 & Chile & Detalles de reserva \\
\hline 6 & México & Detalles de reserva \\
\hline 7 & Argentina & Detalles de reserva \\
\hline 8 & México & Agenda \\
\hline 9 & México & Transacciones \\
\hline
\end{tabular}

Por otra parte, se envió un cuestionario por email (en inglés, usando la plataforma Native Forms) a alojamientos europeos, y se obtuvieron respuestas de seis alojamientos más: 


\begin{tabular}{|c|c|c|}
\hline Alojamiento & País & Sección más usada \\
\hline 10 & Reino Unido & Transacciones \\
\hline 11 & Kosovo & Detalles de reserva \\
\hline 12 & Portugal & Detalles de reserva \\
\hline 13 & República Checa & Detalles de reserva \\
\hline 14 & Austria & Detalles de reserva \\
\hline 15 & Portugal & Detalles de reserva \\
\hline
\end{tabular}

De esta investigación se obtuvo la siguiente información:

1. Respecto de quiénes y dónde usan la plataforma desde un dispositivo móvil:

- Aunque las personas entrevistadas fueron todas dueñas y/o administradoras de alojamientos que, en la mayoría de los casos, habían hecho o hacían tareas de recepción, se mencionó que aquellas personas recepcionistas o voluntarias, hacían uso de la plataforma como solo lectura desde dispositivos móviles, es decir, sin permisos de edición.

- Cuando la plataforma no se usa en versión desktop, se usa mayormente desde un smartphone y no desde una tablet (algo que también pudo observarse en Mixpanel).

- Los usos de la plataforma desde un smartphone se dan tanto dentro como fuera del alojamiento:

- Fuera: cuando están en sus casas, en el auto, en cafés y/o restaurantes, de vacaciones o "haciendo tiempo" (filas en el banco y/o en el banco).

- Dentro: cuando están lejos de la recepción, si la/s computadora/s no funciona/n o está/n ocupada/s, o para responder preguntas de huéspedes en el momento.

2. Respecto de qué quieren hacer y qué hacen:

- Los usos que se le da a la plataforma desde dispositivos móviles se agrupan en tres categorías:

- Control/monitoreo: para esto es que se ve el calendario, detalles de reserva y dashboard. 
- Corrección de errores: para esto es que se ven los detalles de reserva, se modifican reservas y se bloquean camas y/o habitaciones.

- Tareas de recepción y resolución de dudas: para esto es que se ven los detalles de reserva, se crean y modifican reservas, se agregan pagos, se bloquean camas y/o habitaciones y se hacen check-in y check-out.

- Las personas remarcaron la necesidad de tener la información necesaria para poder monitorear y responder consultas, de forma rápida y fácil de ver. También destacaron la necesidad de poder hacer modificaciones con la misma rapidez y facilidad, tanto para corregir errores como para realizar tareas de recepción.

- Ninguna persona entrevistada o encuestada hizo modificaciones en la configuración del alojamiento desde un dispositivo móvil, es algo que prefieren hacer en un momento especial, con tiempo, concentración y desde una computadora. Esto es especialmente relevante, porque indicaría que no sería necesario pasar a una versión mobile esta sección de la plataforma.

3. Respecto de qué limitaciones encuentran:

- Los problemas con que se toparon las personas al usar la plataforma desde un dispositivo móvil pertenecen a dos categorías:

- Visualización: problemas con el tamaño de la pantalla que generan que tengan que hacer (y deshacer) zoom, y que no se visualicen los menús desplegables (dropdown), ya que al desplegarse no se ven dentro de la pantalla.

- Drag \& $d r o p^{39}$ : se pierde por completo esta funcionalidad, lo que hace que no se puedan crear rápidamente reservas para más de una persona y/o más de una noche. Lo mismo ocurre con los bloqueos para más de una cama y/o habitación, y/o para más de una noche.

- Estos problemas generan que la plataforma no se pueda usar correctamente, por lo que a veces las personas comienzan una acción desde un dispositivo móvil pero las completan más tarde en una computadora.

\footnotetext{
${ }^{39}$ La posibilidad de arrastrar y soltar (drag \& drop) las reservas y mover a los huéspedes de una cama o habitación a otra, es una de las funcionalidades que presenta el calendario de la plataforma.
} 
- Además, estos problemas hacen que las personas prefieran evitar usar la plataforma desde un dispositivo móvil para usos determinados, como agregar pagos, para evitar cometer errores.

- Por último, se reportó la imposibilidad de usar la plataforma desde dispositivos móviles de la marca Apple (que usan el navegador Safari, desarrollado por la misma empresa).

Cabe señalar que todos los alojamientos contactados estaban abiertos al momento de interactuar con las personas que trabajaban en ellos. Sin embargo, en algunos casos, debieron estar cerrados al turismo por algún tiempo, por medidas sanitarias. En otros casos, no pudieron cerrar, por tener huéspedes varados que se alojaban allí.

En el caso de las personas que trabajaban en alojamientos que tuvieron que cerrar, accedían a la plataforma desde sus dispositivos móviles, al no poder hacerlo desde la computadora de la recepción. Algunas de las personas encuestadas, dejaron de usar la plataforma desde estos dispositivos cuando pudieron volver a trabajar desde las computadoras de los alojamientos.

En las entrevistas, se hizo reiteradas veces alusión a los usos en el contexto previo a la pandemia y al de la pandemia misma, y las personas coincidieron en que éstos no variaron, lo que muestra que las necesidades, usos y problemas identificados son independientes del contexto. Asimismo, como expectativas para el contexto post-pandemia, las personas coincidieron en que el uso de la plataforma desde dispositivos móviles va a mantenerse igual o a crecer, pero no va a disminuir. 


\subsection{Alternativas de desarrollo}

Para el desarrollo de este apartado se consultó, durante los meses de julio y agosto de 2021, a cinco personas que trabajan como desarrolladoras en distintas cooperativas de desarrollo de software y/o empresas. Se realizaron dos instancias de consulta con cada persona, a través de formularios de Google Forms enviados por email ${ }^{40}$.

Las personas consultadas tienen las siguientes especialidades y pertenecen a las siguientes cooperativas o empresas:

\begin{tabular}{|c|c|c|}
\hline Persona consultada & Especialidad & Cooperativa o empresa \\
\hline 1 & Desarrollador Full Stack & Gaia $^{41}$ \\
\hline 2 & Desarrollo de Software / Programación & Eryx $^{42}$ \\
\hline 3 & IT & Despegar \\
\hline 4 & Tech Support Engineer - L3 & Tiendanube \\
\hline 5 & Desarrollo Backend / Data & Despegar \\
\hline
\end{tabular}

Inicialmente, se establecieron ciertos criterios considerados relevantes a tener en cuenta a la hora de un eventual desarrollo. Estos criterios, que fueron ponderados con valores entre 1 (lo más desfavorable para BananaDesk) y 5 (lo más favorable para la empresa), fueron los siguientes:

\begin{tabular}{|l|r|}
\hline \multicolumn{1}{|c|}{ Criterios } & Ponderación (P) \\
\hline Costo (precio) & 1 \\
\hline Tiempo (horas) & 2 \\
\hline Dificultad de desarrollo & 3 \\
\hline Dificultad de implementación & 3 \\
\hline Performance final esperada & 2 \\
\hline Articulación con la plataforma ya existente & 1 \\
\hline Facilidad para escalar en el futuro & 3 \\
\hline
\end{tabular}

\footnotetext{
${ }^{40}$ Las preguntas que se usaron pueden verse en el Anexo 3.

${ }^{41}$ Esta cooperativa lleva adelante el desarrollo de BananaDesk desde enero de 2021.

${ }^{42}$ Esta cooperativa llevó adelante el desarrollo de BananaDesk desde mediados de 2015 hasta diciembre de 2020.
} 
Una vez establecidos y ponderados los criterios, se procedió a la consulta de las personas mencionadas. La primera instancia de consulta se llevó a cabo con el fin de entender cuáles eran las distintas alternativas posibles de desarrollo. Las alternativas que se identificaron como posibles, luego de unificar todas las respuestas obtenidas en la primera instancia de consulta, fueron:

- Optimización de la visualización: actualizando el frontend ${ }^{43}$ y ajustando lo necesario para lograr una correcta visualización responsive $e^{44}\left(\mathrm{HTML}_{\mathrm{TCSS}}{ }^{45}\right)$.

- Desarrollo de apps mobile $e^{46}$ nativas: esto contemplaría dos desarrollos, uno para Android y otro para iOS ${ }^{47}$.

- Desarrollo de apps mobile con una solución híbrida: usando una tecnología híbrida (como Ionic o React Native ${ }^{48}$ ) que permita desde un código base, con un lenguaje frontend "multiplataforma", hacer un desarrollo para web, Android e iOS.

Una vez comprendido este aspecto, se procedió a cruzar las alternativas con los criterios y se pidió, en la segunda instancia de consulta, que se puntuara del 1 al 5 la situación de cada alternativa frente a cada criterio. Considerando siempre al valor 1 como el más bajo (menor costo, menos horas, menor dificultad, peor performance, peor articulación, menor facilidad) y al valor 5 como el más alto (mayor costo, mayor cantidad de horas, mayor dificultad, mejor performance, mejor articulación, mayor facilidad). Se pidió que, al momento de puntuar, se considerara la situación de las alternativas de manera relativa.

A las personas se les pidió que puntuaran pensando en 1 como el valor más bajo y 5 como el más alto. Como estos valores para la empresa pueden no ir en la misma dirección,

\footnotetext{
${ }^{43}$ El frontend es la interfaz que ve y con la que interactúa la persona usuaria.

${ }^{44}$ Una web responsive o adaptable, es aquella que puede adaptarse a cualquier dispositivo y ser visualizada correctamente.

${ }^{45}$ EI HTML, del inglés HyperText Markup Language (Lenguaje de Marcas de Hipertexto), es el componente que define el significado y la estructura del contenido de una web. Por su parte, el CSS, del inglés Cascading Style Sheets (Hojas de Estilo en Cascada), es el lenguaje de estilos utilizado para describir la presentación de documentos HTML (definiciones disponibles en: https://developer.mozilla.org/es/docs/Web).

${ }^{46}$ Una app mobile, o aplicación móvil, es una aplicación informática que se diseña y desarrolla para poder ser utilizada correctamente en dispositivos móviles, como smartphones o tablets.

${ }^{47}$ Android e iOS son sistemas operativos para dispositivos móviles. Mientras Android es el más ampliamente difundido, iOS es el sistema operativo específico de los dispositivos de la marca Apple.

${ }^{48}$ Aunque tienen diferencias, tanto lonic y React Native son frameworks (estructuras tecnológicas) con las que se pueden crear aplicaciones híbridas. Estas aplicaciones son desarrolladas en un lenguaje de programación a las que se suma un framework (por ejemplo, alguno de los mencionados), para que pueda adaptarse a la visualización desde cualquier dispositivo móvil.
} 
luego se ajustaron las escalas, para que la menor calificación (1) se asocie a la situación más desfavorable y la mayor (5) a la más favorable para BananaDesk. Se presentan a continuación, los puntajes promedio que se obtuvieron al cruzar las alternativas con los criterios:

- Optimización de la visualización:

\begin{tabular}{|l|c|}
\hline \multicolumn{1}{|c|}{ Criterios } & Puntaje promedio \\
\hline Costo (precio) & 3,6 \\
\hline Tiempo (horas) & 2,4 \\
\hline Dificultad de desarrollo & 3,2 \\
\hline Dificultad de implementación & 3,2 \\
\hline Performance final esperada & 3,2 \\
\hline Articulación con la plataforma ya existente & 4 \\
\hline Facilidad para escalar en el futuro & 2,8 \\
\hline
\end{tabular}

- Desarrollo de apps mobile nativas:

\begin{tabular}{|l|c|}
\hline \multicolumn{1}{|c|}{ Criterios } & Puntaje promedio \\
\hline Costo (precio) & 1,2 \\
\hline Tiempo (horas) & 1 \\
\hline Dificultad de desarrollo & 1,4 \\
\hline Dificultad de implementación & 2,2 \\
\hline Performance final esperada & 4,6 \\
\hline Articulación con la plataforma ya existente & 3 \\
\hline Facilidad para escalar en el futuro & 3,4 \\
\hline
\end{tabular}


- Desarrollo de apps mobile con una solución híbrida:

\begin{tabular}{|l|c|}
\hline \multicolumn{1}{|c|}{ Criterios } & Puntaje promedio \\
\hline Costo (precio) & 2 \\
\hline Tiempo (horas) & 2,2 \\
\hline Dificultad de desarrollo & 2,6 \\
\hline Dificultad de implementación & 2,8 \\
\hline Performance final esperada & 4 \\
\hline Articulación con la plataforma ya existente & 3 \\
\hline Facilidad para escalar en el futuro & 4 \\
\hline
\end{tabular}

Los puntajes promedio de cada alternativa, para cada criterio, pueden verse gráficamente a continuación:

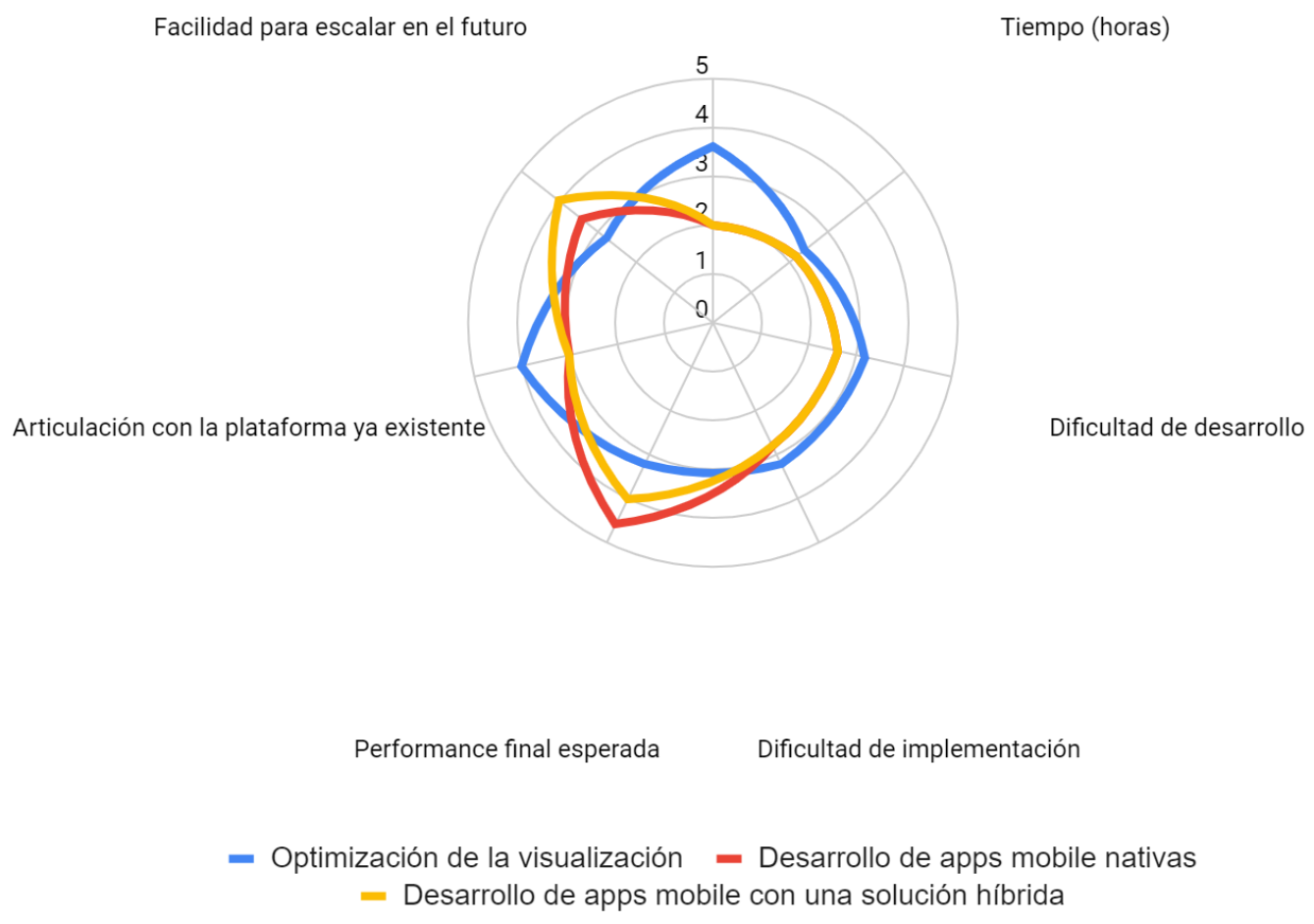


Finalmente, siguiendo los pasos del proceso decisorio, se confeccionó una matriz y se multiplicó, para cada alternativa, el puntaje promedio para cada criterio por su peso ponderado, y se sumaron estos valores, seleccionando la alternativa con el valor total más alto.

Como puede observarse en la tabla, la alternativa con el mayor puntaje fue la primera, la optimización de la visualización, con 50,4 puntos, frente a las dos restantes, el desarrollo de apps nativas y el desarrollo de apps mobile con una solución híbrida, con 39,4 y 48,6 puntos, respectivamente.

En esta elección de esa alternativa como la ganadora, no se tienen en cuenta solo aspectos técnicos. Si así fuera, no sería ésta la mejor opción, como puede verse reflejado en la puntuación referida a la performance, donde tiene el puntaje más bajo. Sin embargo, considerando la situación actual de la empresa, sus recursos y los desarrollos con con que ya cuenta, se vuelven muy relevantes otros aspectos a la hora de evaluar las alternativas (como el menor costo o la mejor articulación con la plataforma existente). Esta elección de la alternativa ganadora, entonces, puede que no sea la mejor opción de desarrollo posible en términos abstractos, sino la que se considera que se adapta mejor a la situación de la empresa en la que se enfoca este trabajo. 


\begin{tabular}{|c|c|c|c|c|c|c|c|c|c|c|c|c|c|c|c|}
\hline \multirow[b]{2}{*}{ Alternativas } & \multicolumn{14}{|c|}{ Criterios y ponderaciones } & \multirow[b]{2}{*}{ Total } \\
\hline & $\begin{array}{c}\text { Costo } \\
\text { (precio) }\end{array}$ & $P$ & $\begin{array}{l}\text { Tiempo } \\
\text { (horas) }\end{array}$ & $\mathrm{P}$ & $\begin{array}{c}\text { Dificultad de } \\
\text { desarrollo }\end{array}$ & $P$ & $\begin{array}{l}\text { Dificultad de } \\
\text { implementa- } \\
\text { ción }\end{array}$ & $P$ & $\begin{array}{c}\text { Performance } \\
\text { final } \\
\text { esperada }\end{array}$ & $P$ & $\begin{array}{c}\text { Articulación } \\
\text { con la } \\
\text { plataforma } \\
\text { ya existente }\end{array}$ & $\mathrm{P}$ & $\begin{array}{c}\text { Facilidad } \\
\text { para escalar } \\
\text { en el futuro }\end{array}$ & $P$ & \\
\hline $\begin{array}{c}\text { Optimización de la } \\
\text { visualización }\end{array}$ & 3,6 & 1 & 2,4 & 2 & 3,2 & 3 & 3,2 & 3 & 3,2 & 2 & 4 & 1 & 2,8 & 3 & 50,4 \\
\hline $\begin{array}{c}\text { Desarrollo de apps } \\
\text { mobile nativas }\end{array}$ & 1,2 & 1 & 1 & 2 & 1,4 & 3 & 2,2 & 3 & 4,6 & 2 & 3 & 1 & 3,4 & 3 & 39,4 \\
\hline $\begin{array}{c}\text { Desarrollo de apps } \\
\text { mobile con una } \\
\text { solución híbrida }\end{array}$ & 2 & 1 & 2,2 & 2 & 2,6 & 3 & 2,8 & 3 & 4 & 2 & 3 & 1 & 4 & 3 & 48,6 \\
\hline
\end{tabular}




\section{Propuesta de intervención}

\section{1) Síntesis del problema}

Como se mencionó al inicio de este trabajo, la ausencia de una versión de la plataforma que sea compatible con dispositivos móviles como smartphones y tablets, no es solo un problema, sino una debilidad importante para BananaDesk en el contexto actual.

Considerando, entonces, la situación actual de la empresa, las necesidades de las personas usuarias y la mejor alternativa posible para ese desarrollo, se presenta la siguiente propuesta de intervención.

\section{2) Objetivo}

Con esta propuesta se busca delinear el proceso de desarrollo y comunicación de una versión de la plataforma que sea compatible con dispositivos móviles como smartphones y tablets. Asimismo, la intención es que sirva de guía para la empresa, ya que se tienen en consideración tanto su situación actual como el contexto del mercado y las necesidades de quienes usan la plataforma.

\section{3) Estrategia a implementar}

De acuerdo al concepto de estrategia que se considera en este trabajo no debe ignorarse el contexto en la toma de decisiones.

Existe, como ya se ha referenciado, una marcada tendencia global al uso de dispositivos móviles que, además, se vio potenciada por la pandemia de COVID-19. Ésta generó una aceleración en la digitalización de ciertos sectores y regiones que provoca que sea imprescindible, para cualquier tipo de organización, tener presencia en dispositivos móviles.

En cuanto al contexto competitivo en el que se encuentra la empresa, se espera una recuperación de la actividad turística que, ante unas mismas barreras de entrada altas, podría aumentar la rivalidad entre los actores existentes, haciendo aún más relevante potenciar las fortalezas, mitigar las debilidades y hacer foco en las propuestas de valor, para 
poder aprovechar y captar parte de estos nuevos alojamientos que demanden plataformas de gestión.

En este sentido, se propone ejecutar un plan de desarrollo y comunicación que, por un lado, ataque el problema de la ausencia de una versión mobile de la plataforma y, por el otro, vuelva visible la nueva implementación para clientes actuales y potenciales. Este plan, de acuerdo con la clasificación presentada anteriormente, sería un plan operativo, de corto plazo, específico y permanente.

Este plan busca robustecer a la empresa frente a la amenaza de la tendencia mundial al uso de los dispositivos móviles que exige tener esta versión y que muchos competidores ya tienen. Por otra parte, hace frente a las tres principales debilidades identificadas: la poca cantidad de clientes y el consecuentemente lento crecimiento de la facturación y de la empresa; la ausencia de acciones de marketing que busquen a revertir esta situación, apuntando a la conversión de nuevos clientes; y la mencionada ausencia de una versión mobile.

El desarrollo debe considerar lo intuitiva que es la plataforma y, por eso, lo fácil que resulta aprender y enseñar a usarla, una de las principales propuestas de valor de BananaDesk. Es imprescindible que la versión mobile no pierda este atributo.

Otra propuesta de valor a mantener es el asesoramiento y trato personalizado que se da desde el primer momento, explicando el funcionamiento de la plataforma y ayudando a configurar la cuenta. Es indispensable que este aspecto se conserve frente a las dudas y consultas que puedan presentarse por parte de clientes actuales y potenciales, una vez que se implemente y comunique la existencia de una versión mobile.

\section{4) Descripción de tareas a desarrollar}

El plan estará compuesto por dos partes. La primera será la de desarrollo, a su vez conformada por tres etapas:

1. Investigación e ideación: esta etapa se llevará a cabo con una perspectiva UX, pensando siempre en la experiencia de la persona usuaria. En base a la información obtenida de las entrevistas mencionadas en el apartado 5.2., se confeccionarán 
mapas de empatía y user jouney $\operatorname{maps}^{49}$, para entender mejor cómo son y qué recorrido hacen las personas que usarán la versión en dispositivos móviles. Para elaborarlos, por ejemplo, es relevante tener en cuenta que la plataforma se usa desde un smartphone en situaciones tanto dentro como fuera del alojamiento. $\mathrm{O}$ que, como se mencionó anteriormente, las personas entrevistadas remarcaron la necesidad de tener la información necesaria para poder monitorear y responder consultas, de forma rápida y fácil de ver, así como de poder hacer modificaciones con la misma rapidez y facilidad, tanto para corregir errores como para realizar tareas de recepción.

La siguiente tarea será la elaboración de wireframes y wireflows ${ }^{50}$. En este punto, es relevante tener en cuenta que, en las entrevistas, se señaló que los usos que se le da a la plataforma desde dispositivos móviles se agrupan en tres categorías:

- Control/monitoreo: para esto es que se ve el calendario, detalles de reserva y dashboard.

- Corrección de errores: para esto es que se ven los detalles de reserva, se modifican reservas y se bloquean camas y/o habitaciones.

- Tareas de recepción y resolución de dudas: para esto es que se ven los detalles de reserva, se crean y modifican reservas, se agregan pagos, se bloquean camas y/o habitaciones y se hacen check-in y check-out.

Por último, como ninguna persona entrevistada o encuestada hizo modificaciones en la configuración del alojamiento desde un dispositivo móvil (porque es algo que prefieren hacer en un momento especial, con tiempo, concentración y desde una computadora), algo que se veía antes desde las métricas de Mixpanel (donde la sección de configuración no se encontraba entre las más visitadas), no se considera necesaria la incorporación de esta sección. Se puede obviar el desarrollo de la optimización de esta sección para mobile, y hacer que no se muestren los botones que llevan a esa sección.

\footnotetext{
${ }^{49}$ Un mapa de empatía busca mostrar qué ve, dice, escucha y hace una persona usuaria arquetípica. Un user journey map presenta los momentos, acciones y emociones que ocurren antes, durante y después de la experiencia de uso.

${ }^{50}$ Un wireflow sirve para graficar el recorrido y las interacciones que hace una persona usando la plataforma, pudiendo verlas en un diagrama de flujo. Un wireframe es un esquema a grandes rasgos de una pantalla.
} 
2. Prototipado, testeo y diseño: esta etapa, al igual que la anterior, tendrá un enfoque en la experiencia de las personas que usen la plataforma. Se elaborarán, en base a los wireframes y wireflows, los prototipos en baja fidelidad de las vistas de todas las secciones de la plataforma. Ese prototipo deberá testearse con personas usuarias, para poder saber si es intuitivo y fácil de usar, si las personas lo entienden y cómo es la experiencia de uso. Esto sirve para saber si es necesario hacer modificaciones previas a la elaboración de estos prototipos en media y alta fidelidad.

3. Desarrollo e implementación: como se vio en el apartado 5.3., consultando a personas que se dedican al desarrollo de software y siguiendo las etapas del proceso decisorio, se decidió optar por la optimización de la visualización de la plataforma, para que lo que hoy es la versión desktop pueda visualizarse correctamente desde dispositivos móviles. Se considera que esa es la mejor alternativa considerando la situación actual de la empresa, sus recursos y los desarrollos con con que ya cuenta.

Se debe prestar especial atención a los problemas con que se toparon las personas entrevistadas al usar la plataforma desde un dispositivo móvil, mencionados anteriormente, relacionados con la visualización y el $d r a g \& d r o p$.

En momentos intermedios durante el desarrollo se harán revisiones y testeos por partes de otras áreas, para identificar y reportar errores eventuales que pudieran surgir.

La segunda parte del plan será la de comunicación. Cabe destacar que la comunicación y el marketing no son temas que se hayan desarrollado en este trabajo. Esta parte del plan se propone únicamente como una alternativa que contribuya, como se mencionó, a visibilizar el desarrollo de la versión mobile de la plataforma, a atacar las debilidades de BananaDesk y a mejorar su posición en un entorno que apunta a volverse más competitivo con el paso del tiempo. A su vez, esta parte estará conformada por dos etapas:

1. Ideación: en esta etapa se debe desarrollar un plan de marketing que apunte a poder comunicar, tanto a clientes actuales como potenciales, el nuevo desarrollo y 
posibilidad de usar la plataforma desde dispositivos móviles. Se debe identificar, y conseguir, las herramientas necesarias para poder llevarlo adelante, y confeccionar todas las piezas de comunicación necesarias: imágenes para posteos en redes sociales, posteos para el blog, mensajes para mensajes por Intercom, textos para armar secuencias de emails para campañas de email marketing, etc.

2. Puesta a punto e implementación: en esta etapa se deben programar publicaciones y envíos, para poder implementar el plan una vez terminado el desarrollo. El rol del soporte en este punto es muy importante, ya que es el área que está en mayor contacto con clientes actuales, pero también con quienes desean contratar la plataforma. El feedback que reciban, sea positivo o negativo, sirve para todas las áreas y es imprescindible para que la empresa pueda evaluar inicialmente el impacto de la noticia y los primeros usos de la plataforma en su versión optimizada para dispositivos móviles.

Es imprescindible propiciar la comunicación interna y el trabajo interdisciplinario y en equipo, por eso generalmente no habrá un único área responsable por tarea. El orden en que se mencionan las áreas, cuando interviene más de una, sitúa primero a la que cuenta con una mayor responsabilidad. A continuación se presenta un diagrama de Gantt que muestra, para cada etapa, las tareas previstas, los plazos estimados y las áreas a cargo: 


\begin{tabular}{|c|c|c|c|c|c|c|c|c|c|c|c|c|c|c|c|c|c|}
\hline \multirow{2}{*}{ Tareas } & \multirow{2}{*}{ Responsables } & \multicolumn{16}{|c|}{ Semanas } \\
\hline & & 1 & 2 & 3 & 4 & 5 & 6 & 7 & 8 & 9 & 10 & 11 & 12 & 13 & 14 & 15 & 16 \\
\hline \multicolumn{18}{|c|}{ Desarrollo - Etapa 1 - Investigación e ideación } \\
\hline Confección de mapas de empatía y user journey maps & Investigación & & & & & & & & & & & & & & & & \\
\hline Elaboración de wireframes y wireflows & Investigación y diseño & & & & & & & & & & & & & & & & \\
\hline \multicolumn{18}{|c|}{ Desarrollo - Etapa 2 - Prototipado, testeo y diseño } \\
\hline Elaboración de prototipos en baja fidelidad & Diseño & & & & & & & & & & & & & & & & \\
\hline Testeo de esos prototipos con personas usuarias & Investigación & & & & & & & & & & & & & & & & \\
\hline Elaboración de prototipos en media y alta fidelidad & Diseño, contenidos e investigación & & & & & & & & & & & & & & & & \\
\hline \multicolumn{18}{|c|}{ Desarrollo - Etapa 3 - Desarrollo e implementación } \\
\hline Desarrollo de la optimización de la visualización & Desarrollo & & & & & & & & & & & & & & & & \\
\hline Testeo del desarrollo & Soporte, investigación y desarrollo & & & & & & & & & & & & & & & & \\
\hline Verificación de la correcta aplicación del diseño de las vistas & Desarrollo y diseño & & & & & & & & & & & & & & & & \\
\hline \multicolumn{18}{|c|}{ Comunicación - Etapa 1 - Ideación } \\
\hline Ideación de un plan de marketing & Marketing & & & & & & & & & & & & & & & & \\
\hline Identificación de las herramientas para implementar el plan & Marketing & & & & & & & & & & & & & & & & \\
\hline Confección de los contenidos para implementar el plan & Contenidos y marketing & & & & & & & & & & & & & & & & \\
\hline \multicolumn{18}{|c|}{ Comunicación - Etapa 2 - Puesta a punto e implementación } \\
\hline Puesta a punto del plan & Marketing & & & & & & & & & & & & & & & & \\
\hline Implementación del plan & Marketing y soporte & & & & & & & & & & & & & & & & \\
\hline
\end{tabular}


Se recomienda llevar adelante estas tareas usando una herramienta como Trello o Jira, que permiten trabajar colaborativamente usando el método Kanban que, como se indicó, permite bajar el plan ideal a la operación real, sin perder la organización.

\section{5) Acciones para evaluar la implementación}

Por último, todo plan debe terminar con acciones para evaluar cómo impactó su implementación en la empresa. Para este caso, se proponen distintas formas de evaluación:

\section{- Cuantitativas}

- Medir en Mixpanel los nuevos registros, conversiones y deserciones (churns) desde la implementación del plan.

- Medir el impacto en la facturación.

- Contrastar estas mediciones con períodos anteriores.

- Monitorear en Mixpanel si se modifica la proporción de uso en dispositivos móviles.

- Monitorear en Mixpanel si se modifican los usos de las distintas secciones de la plataforma desde dispositivos móviles.

\section{- Cualitativas}
- Coordinar entrevistas con clientes para indagar sobre su experiencia de uso.
- Confeccionar y distribuir encuestas de satisfacción.
- Monitorear eventuales comentarios y/o reseñas online.

La información que se obtenga en base a estas acciones es sumamente relevante, no solo para evaluar el plan e implementar lo más rápido posible las mejoras que pueda requerir, sino para pensar planes futuros. Por otra parte, el ejercicio del control para la retroalimentación de procesos, y no solo para la evaluación de decisiones ya tomadas, es un excelente ejercicio para cualquier empresa, ya que la vuelve más flexible y conocedora de sí misma. 


\section{Conclusiones}

Este trabajo de aplicación práctica se enfocó en el caso de BananaDesk y en su necesidad de desarrollar una versión mobile de su plataforma. Esta necesidad responde, por un lado, a la tendencia internacional al creciente uso de los dispositivos móviles, potenciada por la pandemia de COVID-19; por otro lado, al contexto competitivo de la empresa, donde la ausencia de una versión mobile es una debilidad importante, y lo será cada vez más.

Como se mencionó inicialmente, la pandemia no solo afectó al turismo en términos cuantitativos como ninguna otra crisis lo había hecho, sino que también lo ha hecho cualitativamente, modificando las prácticas sociales en torno a los viajes. En consecuencia, aparecen turistas que buscan nuevas formas de viajar y de vivir sus experiencias antes, durante y después del viaje.

Frente a estos cambios, la digitalización de todos los actores de la cadena se vuelve imprescindible para no quedar fuera del negocio. En ese sentido, cuantas más posibilidades de digitalización pueda ofrecer BananaDesk a alojamientos independientes, que son sus clientes, mejor se encontrará posicionada en el contexto competitivo.

Con el objetivo último de proponer un plan de acción que pueda resolver la falta actual de una versión mobile de la plataforma, en este trabajo se evaluó, haciendo uso de distintas herramientas de diagnóstico organizacional, la situación actual de BananaDesk, tanto internamente como en interacción con su contexto competitivo. Asimismo, se identificaron los puntos más relevantes para las personas usuarias en torno al uso de la plataforma en dispositivos móviles, precisando quiénes y dónde la usan, qué quieren hacer y qué hacen. También se señalaron algunas limitaciones que se encontraron en su uso. Por último, se valoró, junto con personas que se dedican al desarrollo de software, la situación de distintas alternativas posibles de desarrollo de una versión mobile, y se eligió la que mejor se ajusta a BananaDesk: la optimización de la visualización, actualizando el frontend y ajustando lo necesario para lograr una correcta visualización responsive.

La recopilación de información, el procesamiento de datos y el arribo a conclusiones en cada uno de estos objetivos específicos proporcionó un entendimiento profundo de la 
situación. Sin embargo, los diagnósticos en sí no son útiles: solo lo son si se los usa para tomar decisiones.

Por esta razón, este trabajo culmina con la propuesta concreta de un plan de desarrollo y comunicación claro y preciso que permita, en un plazo estimado de dieciséis semanas, crear y divulgar una versión mobile de la plataforma. Se detallaron las tareas y responsables correspondientes para poder llevar a cabo el plan.
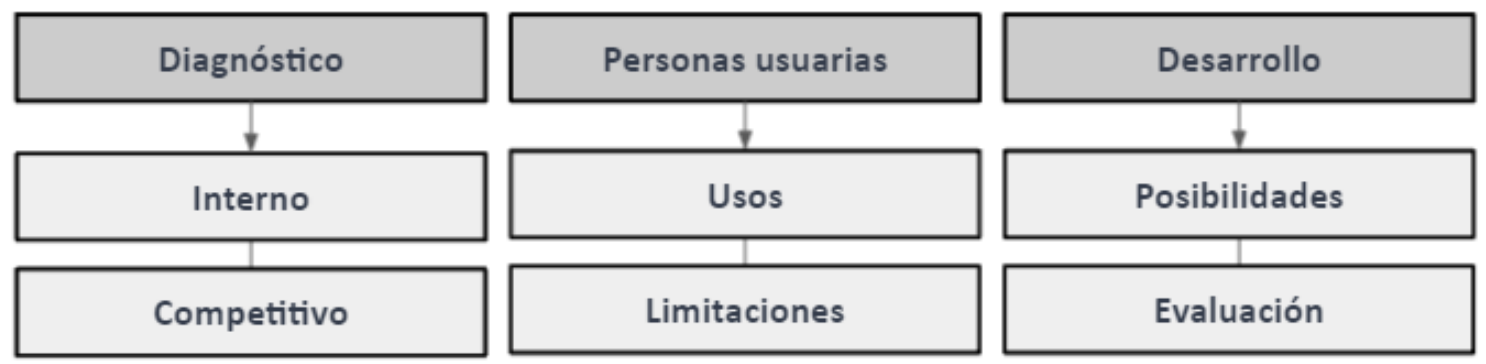

Limitaciones

Evaluación

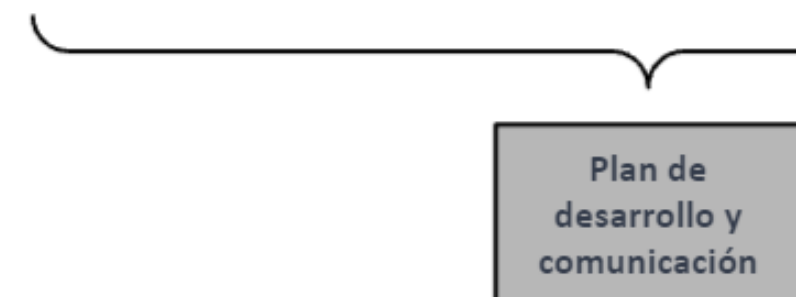

Se espera que la elaboración de este trabajo no solo sirva para BananaDesk, sino que pueda ser una guía para otras empresas que también hayan desarrollado sus productos digitales en formato desktop, y que requieran, por el contexto global actual, adaptarlos para su uso en dispositivos móviles.

Finalmente, se recomienda enérgicamente contemplar distintas fuentes de información, traducirlas en planes estratégicos que establezcan objetivos y acciones concretas, operativizar estos planes, asignar tareas y responsabilidades, evaluar la ejecución e implementar rápidamente las mejoras necesarias. Esto constituye un sano ejercicio para cualquier empresa, ya que la vuelve más flexible, adaptable y conocedora de sí misma y de su entorno. Así, se pueden crear nuevas y acertadas líneas de intervención frente a diversas situaciones, en un contexto dinámico y en constante cambio. 


\section{Referencias teóricas}

\section{Bibliografía}

Ahmad, M. O., Markkula, J., \& Oivo, M. (2013). Kanban in software development: A systematic literature review. En: 39th Euromicro Conference on Software Engineering and Advanced Applications (pp. 9-16). Institute of Electrical and Electronic Engineers, New Jersey, Estados Unidos.

Cygler, J., Sroka, W., Solesvik, M., \& Dębkowska, K. (2018). Benefits and drawbacks of coopetition: The roles of scope and durability in coopetitive relationships. Sustainability, 10(8). Disponible en: https://www.researchgate.net/publication/326758498_Benefits_and_Drawbacks_of _Coopetition_The_Roles_of_Scope_and_Durability_in_Coopetitive_Relationships.

Díaz, C. F. G., \& Ortiz, J. K. R. (2013). Teorías de la cultura organizacional. Disponible en: http://teoriaycomorg.sociales.uba.ar/wp-content/uploads/sites/98/2019/03/Teorias delaCulturaOrganizacionalCarlosGomezyJennyRodriguezrevision2013.pdf.

Klement, A. (2018). When Coffee and Kale Compete: Become Great at Making Products People Will Buy. 2a. Edición. CreateSpace, Carolina del Sur, Estados Unidos.

Kotler, P. (2001). Dirección de Mercadotecnia. Análisis, Planeación, Implementación y Control. 8a Edición. ESAN, Lima, Perú.

Minsal Pérez, D., \& Pérez Rodríguez, Y. (2007). Organización funcional, matricial...: en busca de una estructura adecuada para la organización. Acimed, 16(4). Disponible en: http://scielo.sld.cu/pdf/aci/v16n4/aci101007.pdf. 
Norman, D. \& Nielsen, J. (s.f.). The Definition of User Experience (UX). Norman Nielsen Group.

https://www.nngroup.com/articles/definition-user-experience/.

Osterwalder, A., \& Pigneur, Y. (2010). Business Model Generation: A Handbook for Visionaries, Game Changers, and Challengers. John Wiley \& Sons, Nueva Jersey, Estados Unidos.

Otero, D., \& Gache, F. L. (2006). Evoluciones dinámicas en el diagrama FODA. Revista Cientifica "Visión de Futuro", 6(2). Disponible en: https://www.redalyc.org/pdf/3579/357935465001.pdf.

Porter, M. (2008a). Las cinco fuerzas competitivas que le dan forma a la estrategia. Harvard Business Review, 86(1), 58-77.

Porter, M. (2008b). ¿Qué es la estrategia? Harvard Business Review, 89(11), 100-117.

Portigal, S. (2013). Interviewing Users: How to Uncover Compelling Insights. Rosenfeld Media, Nueva York, Estados Unidos.

Robbins, S. P., \& Coulter, M. (2014). Administración. 12a. Edición. Pearson, Estado de México, México.

Ronda-Pupo, G. A., \& Guerras-Martin, L. Á. (2012). Dynamics of the evolution of the strategy concept 1962-2008: a co-word analysis. Strategic management journal, 33(2), $162-188$

Talancón, H. P. (2007). La matriz FODA: alternativa de diagnóstico y determinación de estrategias de intervención en diversas organizaciones. Enseñanza e Investigación en Psicología, 12(1), 113-130. 
Terrazas Pastor, R. (2011). Planificación y programación de operaciones. Perspectivas, 28, 7-32.

\section{Fuentes}

Becka, L., Cimatti, M. L., Giraldo, J. y González Botasi, S. (2021). Plan estratégico BananaDesk. Trabajo final de Estrategia Empresarial y Gestión de Riesgos, Maestría en Dirección de Empresas, Facultad de Ciencias Económicas de la Universidad Nacional de La Plata, Argentina. Manuscrito no publicado.

Cimatti, M. L. (2020). Resumen de Investigación: Mobile. BananaDesk, La Plata, Argentina. Manuscrito no publicado.

UNWTO. (2020). 2020: el peor año de la historia del turismo, con mil millones menos de llegadas internacionales.

Disponible

en: https://webunwto.s3.eu-west-1.amazonaws.com/s3fs-public/2021-01/210128-baro meter-es.pdf?afhE7NpuFgX_3avC5b8GTiE2T7Ptcw9J.

Newzoo. (2020). Global Mobile Market Report 2020. Disponible en: https://newzoo.com/insights/trend-reports/newzoo-global-mobile-market-report-20 20-free-version/.

Stefanini. (2021). El nuevo mundo BANI: la certeza de la incertidumbre en los negocios. Disponible en: https://stefanini.com/es/trends/articulos/el-nuevo-mundobani-la-certeza-de-la-incertidumbre-en-los-negocios. 


\section{Anexo}

1.1. Alojamientos por continente ${ }^{51}$

\begin{tabular}{|c|c|c|}
\hline Continente & Cantidad de Alojamientos & Porcentaje del total \\
\hline América Latina & 126 & $69,61 \%$ \\
\hline América del Norte & 2 & $1,10 \%$ \\
\hline Europa & 35 & $19,34 \%$ \\
\hline Asia & 11 & $6,08 \%$ \\
\hline Oceanía & 3 & $1,66 \%$ \\
\hline África & 4 & $2,21 \%$ \\
\hline Total & 181 & $100,00 \%$ \\
\hline
\end{tabular}

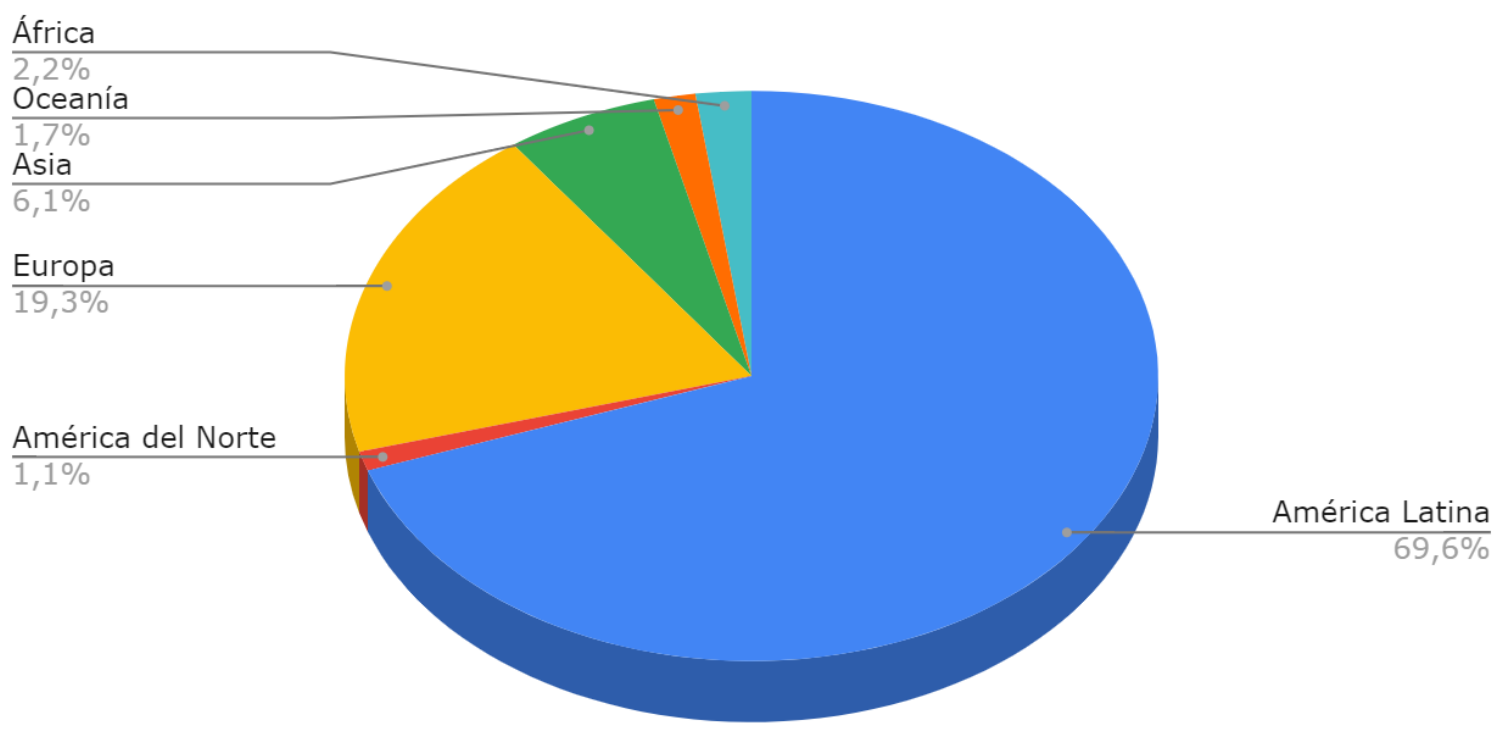

\footnotetext{
${ }^{51}$ Los datos que se presentan en el punto 1 de este Anexo corresponden al 17 de junio del 2021.
} 
1.2. Alojamientos en América Latina

\begin{tabular}{|c|c|c|}
\hline América Latina & Cantidad de Alojamientos & Porcentaje del América Latina \\
\hline Argentina & 34 & $26,98 \%$ \\
\hline México & 25 & $19,84 \%$ \\
\hline Costa Rica & 13 & $10,32 \%$ \\
\hline Chile & 11 & $8,73 \%$ \\
\hline Colombia & 6 & $4,76 \%$ \\
\hline Brasil & 6 & $4,76 \%$ \\
\hline Uruguay & 3 & $2,38 \%$ \\
\hline Ecuador & 11 & $8,73 \%$ \\
\hline Panamá & 5 & $3,97 \%$ \\
\hline Perú & 2 & $1,59 \%$ \\
\hline Guatemala & 6 & $4,76 \%$ \\
\hline Paraguay & 1 & $0,79 \%$ \\
\hline Bolivia & 2 & $1,59 \%$ \\
\hline Venezuela & 1 & $0,79 \%$ \\
\hline Total & 126 & $100,00 \%$ \\
\hline
\end{tabular}

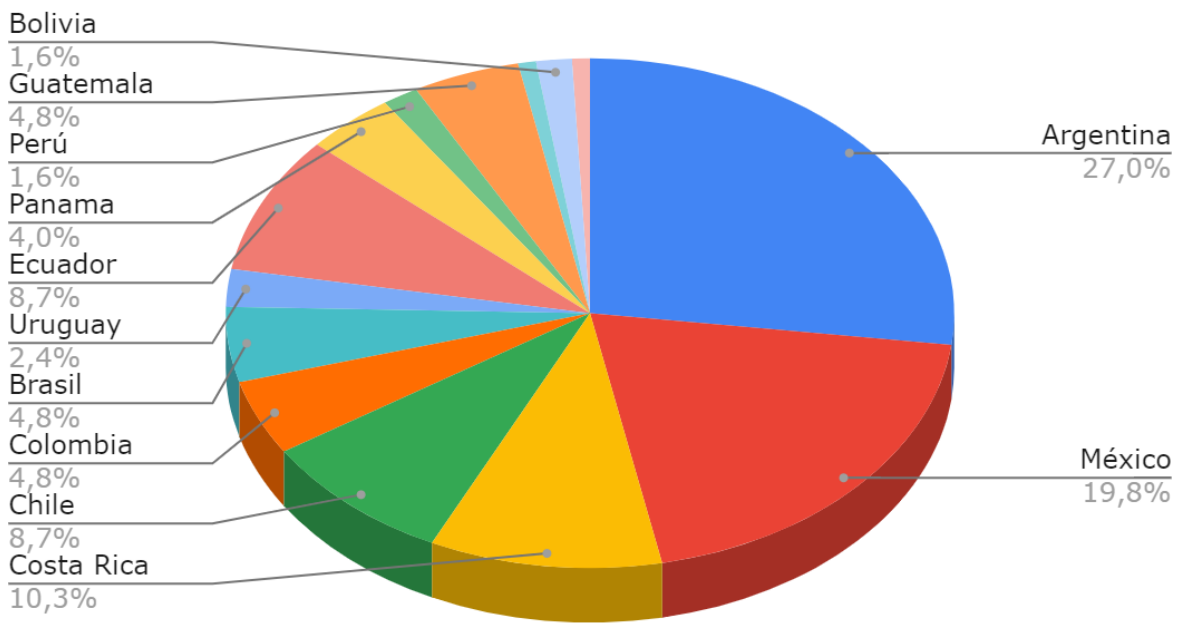


2. Vistas de la plataforma BananaDesk

\section{Calendario}

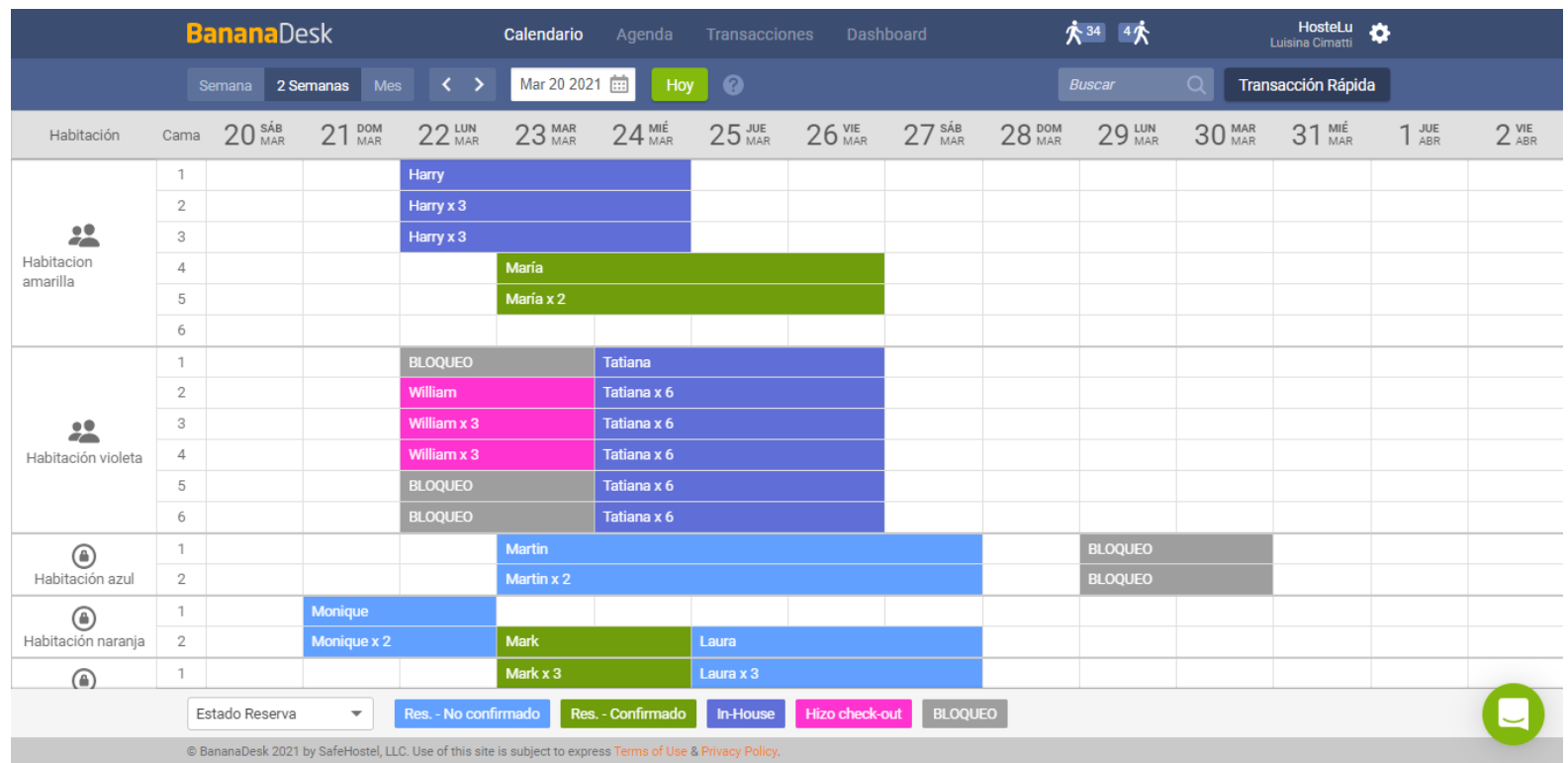

\section{Agenda (Reservas)}

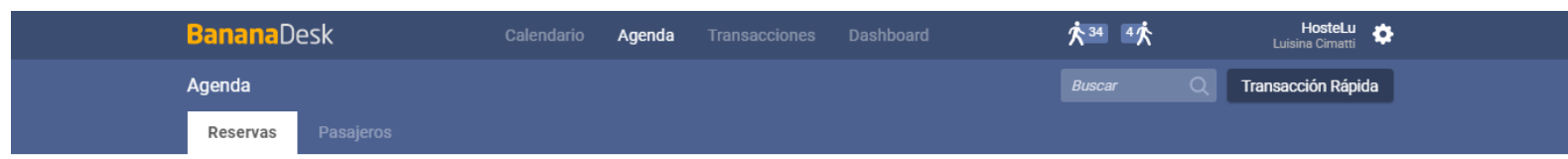

Reservas

\begin{tabular}{|c|c|c|c|c|c|c|c|c|c|}
\hline \multirow{2}{*}{$\begin{array}{l}\text { Filtros: } \\
\text { Estado de Reserva: }\end{array}$} & \multirow{2}{*}{ Aplicar } & \multicolumn{2}{|c|}{ Acción: } & \multicolumn{2}{|c|}{ Selecciona Acción } & \multirow{2}{*}{$\begin{array}{c}\text { Exportar Todo } \\
\text { Balance }\end{array}$} & \multicolumn{3}{|r|}{ Pag. $1<>$} \\
\hline & & $\square$ & Reserva & Estado & Pasajero & & $\begin{array}{l}\text { Pre } \\
\text { Check- } \\
\text { in }\end{array}$ & Llegada & Partida \\
\hline & & $\square$ & 90 & Sin confirmar & Luisina Cimatti & ARS $\$ 2,700.00$ & ○ & Ago. 1, 2020 & Ago. 3, 2020 \\
\hline \multicolumn{2}{|l|}{ Fecha de Creación: } & $\square$ & 91 & Sin confirmar & Luisina Cimatti & ARS $\$ 3,600.00$ & $\ominus$ & Oct. 26,2020 & Oct. 28,2020 \\
\hline \multirow{2}{*}{ Creado por: } & Limpiar Filitro & $\square$ & 92 & Sin confirmar & Luisina Cimatti & ARS $\$ 3,600.00$ & $\bullet$ & Oct. 29,2020 & Oct. 31,2020 \\
\hline & $v$ & $\square$ & 93 & Sin confirmar & juan lopez & ARS $\$ 450.00$ & 0 & Oct. 29,2020 & Oct. 30,2020 \\
\hline \multicolumn{2}{|l|}{ Fecha de Llegada: } & $\square$ & 94 & Sin confirmar & Luisina Cimatti & ARS $\$ 450.00$ & 0 & Oct. 30,2020 & Oct. 31,2020 \\
\hline De 面 $A$ & 畕 & $\square$ & 95 & Sin confirmar & Luisina Cimatti & ARS $\$ 2,700.00$ & $\bullet$ & Nov. 4, 2020 & Nov. 6,2020 \\
\hline \multicolumn{2}{|l|}{ Fecha de salida: } & $\square$ & 96 & Sin confirmar & Verano & ARS $\$ 450.00$ & $\bullet$ & Nov. 24,2020 & Nov. 25,2020 \\
\hline 畕 A & 界 & $\square$ & 97 & In House & Luisina Cimatti & ARS $\$ 450.00$ & $\ominus$ & Dic. 19, 2020 & Dic. 20,2020 \\
\hline \multicolumn{2}{|l|}{ Canal de Reserva: } & $\square$ & 98 & In House & Luisina Cimatti & ARS $\$ 450.00$ & $\ominus$ & Ene. 31, 2021 & Feb. 1, 2021 \\
\hline & & $\square$ & 105 & Sin confirmar & Monique & ARS $\$ 12,000.00$ & $\ominus$ & Mar. 21, 2021 & Mar. 23, 2021 \\
\hline
\end{tabular}




\section{Transacciones (Ingresos)}

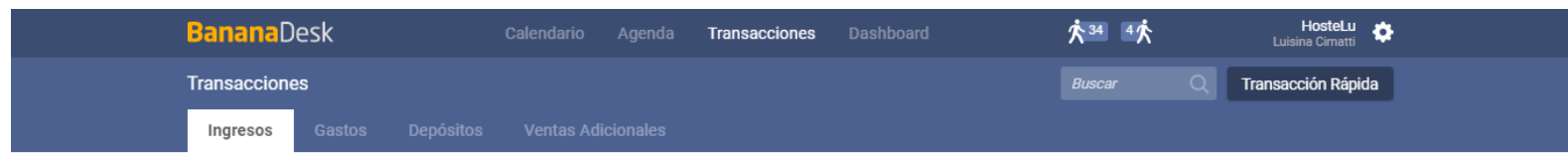

Ingresos

自 Monto filtrado: US $\$ 24,440.40$

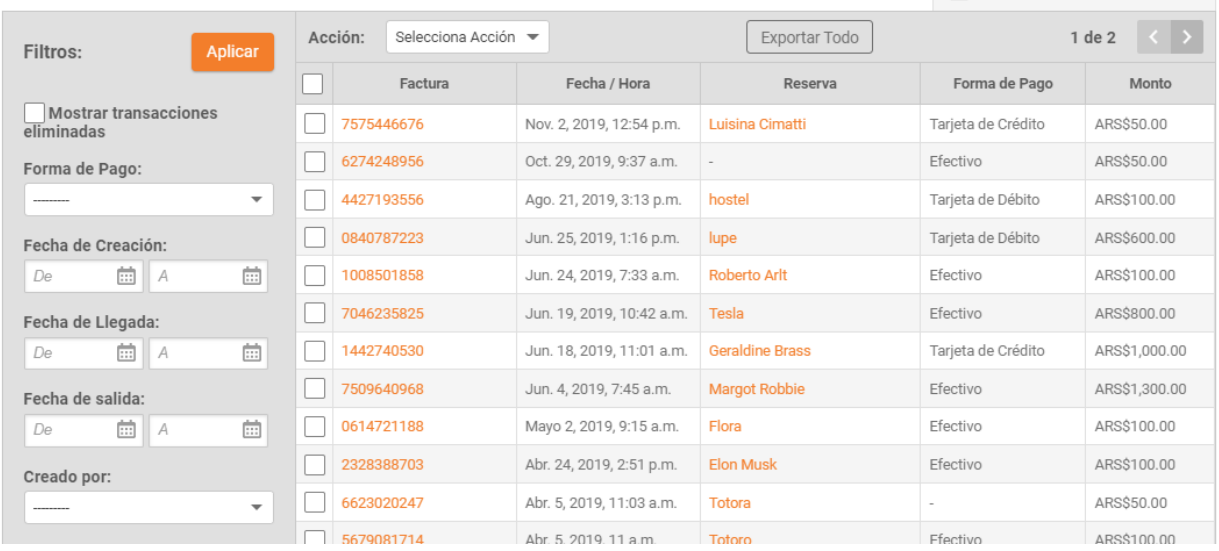

\section{Dashboard (Reportes)}

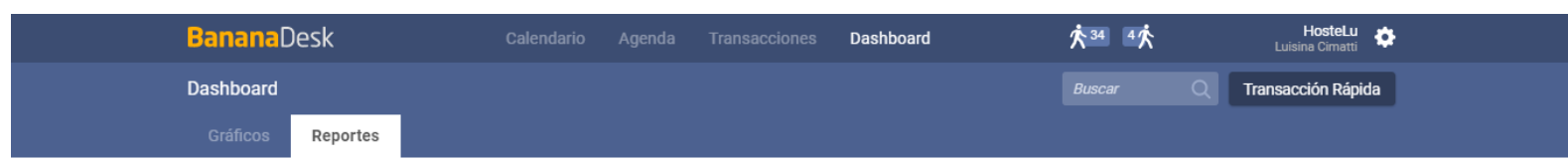

Reportes

Ingresos

Fechas: Jul 12020 进 Jun 302021 囬 Aplicar filtro

\begin{tabular}{|c|c|c|c|c|c|c|c|}
\hline Habitación & No. de Pasajeros & Bed Nights & $\begin{array}{l}\text { Anticipación de } \\
\text { Reservas }\end{array}$ & Ocupación & Tarifa (Promedio) & RevPAB & $\begin{array}{l}\text { Análisis Ingresos } \\
\text { (Alojamiento) }\end{array}$ \\
\hline \multicolumn{8}{|c|}{ Private Room } \\
\hline Doble & 10 & 17 & -2.44 days & $62.96 \%$ & $6,000.00$ USD & 93.15 USD & $102,000.00$ USD \\
\hline Triple & 0 & 0 & 0.00 days & $0.00 \%$ & 0.00 USD & 0.00 USD & OUSD \\
\hline \multicolumn{8}{|l|}{ Dorm Room } \\
\hline $\begin{array}{l}\text { Dormi- } 6 \\
\text { camas }\end{array}$ & 38 & 129 & -0.76 days & $32.58 \%$ & $2,943.97$ USD & 98.32 USD & $430,650.00$ USD \\
\hline \multicolumn{8}{|l|}{ Total } \\
\hline Total & 48 & 146 & -1.12 days & $2.00 \%$ & $3,648.29$ USD & 91.21 USD & $532,650.00$ USD \\
\hline
\end{tabular}




\section{Configuración (Habitaciones / Tarifas base)}

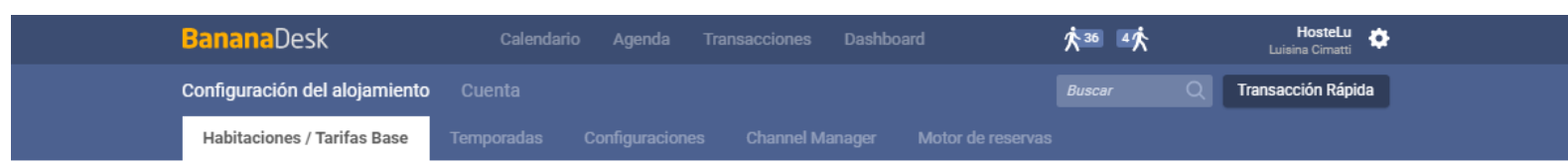

Habitaciones / Tarifas Base

IH Crear Tipo de Habitación

¿Por qué necesito Tipos de Habitación?

\begin{tabular}{|c|c|c|c|c|c|c|c|c|}
\hline $\begin{array}{l}\text { Doble } \\
\text { III Mino Priveda } 2 \text { pax }\end{array}$ & $j$ & Domingo & Lunes & Martes & Miércoles & Jueves & Viernes & Sábado \\
\hline - Habitación azul & & \multirow{3}{*}{$\begin{array}{c}\$ 60.001 \\
\text { habitación }\end{array}$} & \multirow{3}{*}{$\begin{array}{l}\$ 60.00 ! \\
\text { habitación }\end{array}$} & \multirow{3}{*}{$\begin{array}{l}\$ 60.00 ! \\
\text { habitación }\end{array}$} & \multirow{3}{*}{$\begin{array}{l}\text { \$60.00/ } \\
\text { habitación }\end{array}$} & \multirow{3}{*}{$\begin{array}{l}\text { s60.00/ } \\
\text { habitación }\end{array}$} & \multirow{3}{*}{$\begin{array}{c}560.00 / \\
\text { habitación }\end{array}$} & \multirow{3}{*}{$\begin{array}{l}\text { S60.00/ } \\
\text { habitación }\end{array}$} \\
\hline - Habitación celeste & & & & & & & & \\
\hline - Habitación naranja & & & & & & & & \\
\hline \multicolumn{9}{|l|}{ - Crear Habitación } \\
\hline $\begin{array}{l}\text { Dormi - } 6 \text { camas } \\
\text { IIt Mixto Dormi } 6 \text { pax }\end{array}$ & $\gamma$ & Domingo & Lunes & Martes & Miércoles & Jueves & Viernes & Sábado \\
\hline - Habitacion amarilla & & \multirow{2}{*}{$\begin{array}{l}\text { \$35.00/ } \\
\text { persona }\end{array}$} & \multirow{2}{*}{$\begin{array}{l}\$ 35.00 / / \\
\text { persona }\end{array}$} & \multirow{2}{*}{$\begin{array}{l}\$ 35.00 / \\
\text { persona }\end{array}$} & \multirow{2}{*}{$\begin{array}{l}\$ 35.00 / \\
\text { persona }\end{array}$} & \multirow{2}{*}{$\begin{array}{l}\$ 35.00 / \\
\text { persona }\end{array}$} & \multirow{2}{*}{$\begin{array}{l}\$ 35.00 / \\
\text { persona }\end{array}$} & \multirow{2}{*}{$\begin{array}{l}\$ 55.00 / \\
\text { persona }\end{array}$} \\
\hline - Habitación violeta & & & & & & & & \\
\hline - Crear Habitación & & & & & & & & \\
\hline Triple & 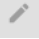 & Domingo & Lunes & Martes & Miércoles & Jueves & Viernes & Sábado \\
\hline
\end{tabular}

\section{Configuración (Channel Manager)}

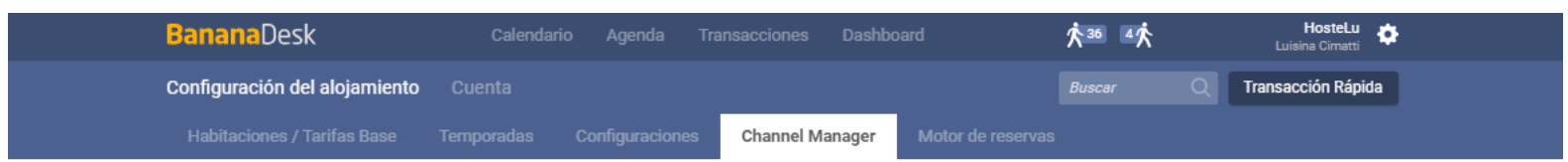

Channel Manager

Conexiones Disponibles

Booking.com

Aún no has conectado tu cuenta con Booking.com.

Conectar

HOSTELWORLD

Aún no has conectado tu cuenta con Hostelworld.

Conectar

Q airbnb

Aún no has conectado tu cuenta con AirBNB. 


\section{Detalles de reserva}

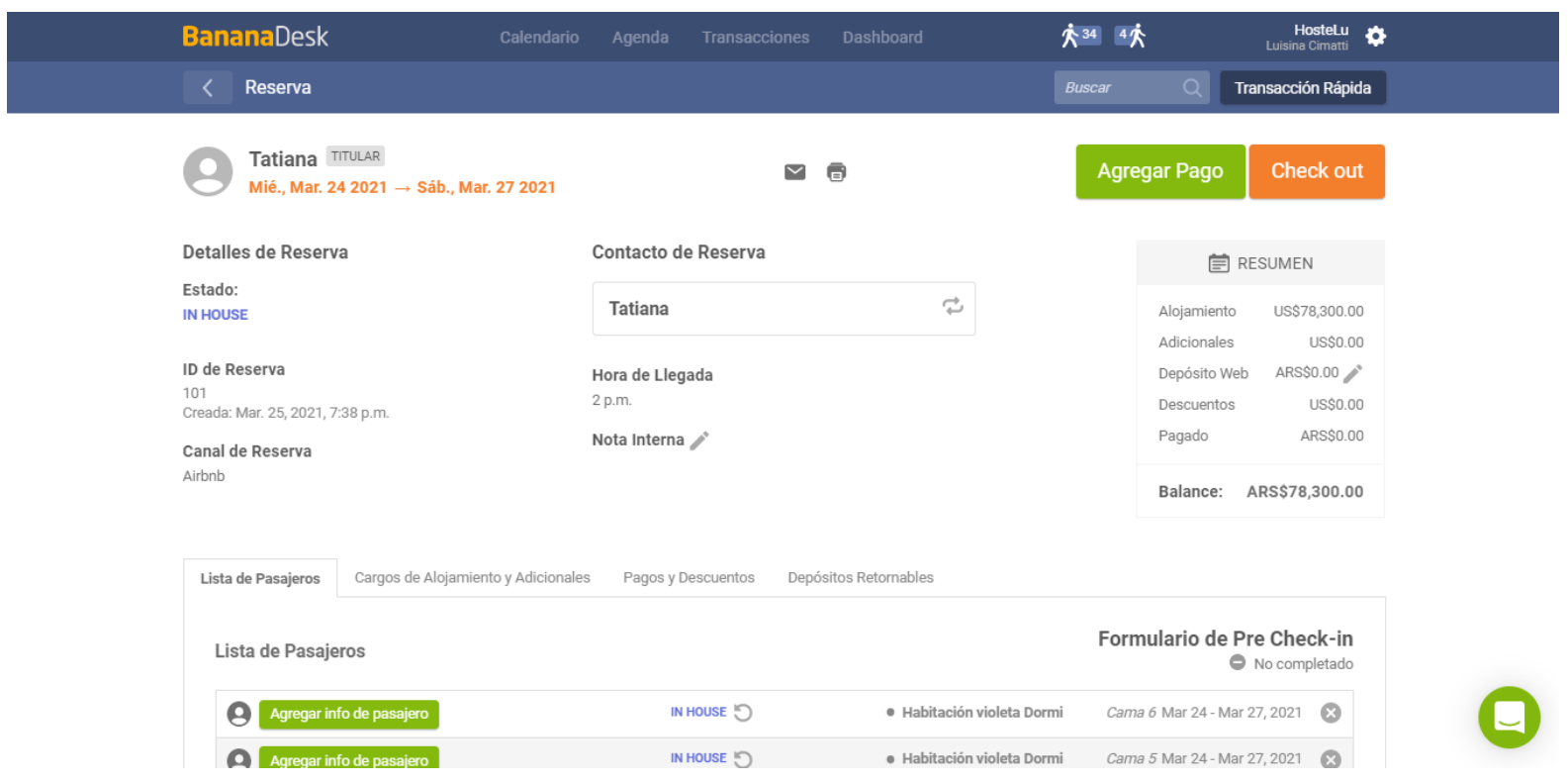


3. Preguntas para la consulta a desarrolladores

\section{Primera instancia de consulta ${ }^{52}$}

- ¿En qué empresa o cooperativa trabajás actualmente?

- ¿Cuál es tu área de expertise?

- Enumerá o listá todas las opciones que consideres posibles para poder lograr que la plataforma pueda usarse correctamente en mobile (sea el desarrollo de una app nativa, de una web app, la optimización de la visualización para que se ajuste a un navegador en mobile, etc.).

\section{Sequnda instancia de consulta}

- Para cada alternativa, por favor puntuá del 1 al 5 su situación frente a cada criterio. Siempre el valor 1 será el más bajo (menor costo, menos horas, menor dificultad, peor performance, peor articulación, menor facilidad) y el valor 5 será el más alto (mayor costo, mayor cantidad de horas, mayor dificultad, mejor performance, mejor articulación, mayor facilidad). La puntuación tiene que considerarse de manera relativa. Por ejemplo, si la primera alternativa es menos costosa que la segunda, que en el primer caso el valor sea 1 y en el segundo, 2.

- Optimización de la visualización: actualizando el frontend y ajustando lo necesario para lograr una correcta visualización responsive (HTML y CSS).

\begin{tabular}{|l|l|l|l|l|l|}
\hline \multicolumn{1}{|c|}{ Criterios } & $\mathbf{1}$ & $\mathbf{2}$ & $\mathbf{3}$ & $\mathbf{4}$ & $\mathbf{5}$ \\
\hline Costo (precio) & & & & & \\
\hline Tiempo (horas) & & & & & \\
\hline Dificultad de desarrollo & & & & & \\
\hline Dificultad de implementación & & & & & \\
\hline Performance final esperada & & & & & \\
\hline Articulación con la plataforma ya existente & & & & & \\
\hline Facilidad para escalar en el futuro & & & & & \\
\hline
\end{tabular}

\footnotetext{
52 Tanto en los emails que se enviaron inicialmente para contactar a la personas consultadas, como en el primer formulario, se agregó información sobre los objetivos de la consulta y sobre las características y la situación actual de la empresa, a modo introductorio.
} 
- Desarrollo de apps mobile nativas: esto contemplaría dos desarrollos, uno para Android y otro para iOS.

\begin{tabular}{|l|l|l|l|l|l|}
\hline \multicolumn{1}{|c|}{ Criterios } & $\mathbf{1}$ & $\mathbf{2}$ & $\mathbf{3}$ & $\mathbf{4}$ & $\mathbf{5}$ \\
\hline Costo (precio) & & & & & \\
\hline Tiempo (horas) & & & & & \\
\hline Dificultad de desarrollo & & & & & \\
\hline Dificultad de implementación & & & & & \\
\hline Performance final esperada & & & & & \\
\hline Articulación con la plataforma ya existente & & & & & \\
\hline Facilidad para escalar en el futuro & & & & & \\
\hline
\end{tabular}

- Desarrollo de apps mobile con una solución híbrida: usando una tecnología híbrida (como lonic o React Native) que permita desde un código base, con un lenguaje frontend "multiplataforma", hacer un desarrollo para web, Android e IOs.

\begin{tabular}{|l|c|c|c|c|c|}
\hline \multicolumn{1}{|c|}{ Criterios } & $\mathbf{1}$ & $\mathbf{2}$ & $\mathbf{3}$ & $\mathbf{4}$ & $\mathbf{5}$ \\
\hline Costo (precio) & & & & & \\
\hline Tiempo (horas) & & & & & \\
\hline Dificultad de desarrollo & & & & & \\
\hline Dificultad de implementación & & & & & \\
\hline Performance final esperada & & & & & \\
\hline Articulación con la plataforma ya existente & & & & & \\
\hline Facilidad para escalar en el futuro & & & & & \\
\hline
\end{tabular}

- ¿Considerás que hay algún/os otro/s criterio/s relevante/s que no tuve en cuenta? ¿Cuál/es? 